RAFAEL RODRIGUES DIAS

Análise linear do septo nasal em pacientes submetidos a expansão rápida de maxila assistida cirurgicamente

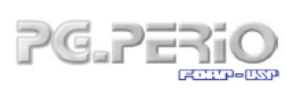

Ribeirão Preto 
RAFAEL RODRIGUES DIAS

\title{
Análise linear do septo nasal em pacientes submetidos a expansão rápida de maxila assistida cirurgicamente
}

\begin{abstract}
Tese apresentada ao programa de Pós-Graduação em Odontologia (Periodontia), área de concentração Cirurgia-Buco-Maxilo-Facial, da Faculdade de Odontologia de Ribeirão Preto da Universidade de São Paulo para obtenção do título de Doutor em Odontologia.
\end{abstract}

Orientador: Prof. Dr. Cássio Edvard Sverzut

Ribeirão Preto 
Autorizo a reprodução e divulgação total ou parcial deste trabalho, por qualquer meio convencional ou eletrônico, para fins de estudo e pesquisa, desde que citada a fonte.

Catalogação na Publicação

Serviço de Documentação Odontológica

Faculdade de Odontologia de Ribeirão Preto da Universidade de São Paulo

Dias, Rafael Rodrigues

Análise linear do septo nasal em pacientes submetidos a expansão rápida de maxila assistida cirurgicamente. Ribeirão Preto, 2018.

69 p. : il. ; $30 \mathrm{~cm}$

Tese apresentada ao programa de Pós-Graduação em Odontologia (Periodontia), área de concentração Cirurgia-BucoMaxilo-Facial, da Faculdade de Odontologia de Ribeirão Preto da Universidade de São Paulo para obtenção do título de Doutor em Odontologia.

Orientador: Sverzut, Cássio Edvard

1. Técnica de Expansão Palatina. 2. Septo Nasal. 3. Tomografia Computadorizada de Feixe Cônico. 4. Cirurgia Bucal. 
Nome: DIAS, Rafael Rodrigues

Titulo: Análise linear do septo nasal em pacientes submetidos a expansão rápida de maxila assistida cirurgicamente

Tese apresentada ao programa de PósGraduação em Odontologia (Periodontia), área de concentração Cirurgia-Buco-Maxilo-Facial, da Faculdade de Odontologia de Ribeirão Preto da Universidade de São Paulo para obtenção do título de Doutor em Odontologia.

Aprovado em:

Banca Examinadora

Prof. Dr.

Instituição: Assinatura:

Prof. Dr.

Instituição:

Assinatura:

Prof. Dr.

Instituição:

Assinatura:

Prof. Dr.

Instituição:

Assinatura:

Prof. Dr.

Instituição: Assinatura: 
Trabalho desenvolvido no Departamento de Cirurgia e Traumatologia Buco-MaxiloFacial e Periodontia da Faculdade de Odontologia de Ribeirão Preto - Universidade de São Paulo, com bolsa de estudos da Coordenação de Aperfeiçoamento de Pessoal de Nível Superior (CAPES) - Ministério da Educação (Cota Institucional). 


\section{DEDICATÓRIA}

Dedico este trabalho às pessoas que mais me deram apoio durante esta jornada de estudos: Meu pai, minha mãe, meu irmão e minha esposa.

Vocês são à base da minha vida.

Sei que fiz todos sofrerem um pouco com meus momentos de dúvida, angústia e ausência. Porém, cada um de vocês teve um papel, direta ou indiretamente, na minha formação, não só como dentista, mas como o homem que sou hoje.

Não tenho palavras pra agradecer o que fizeram.

Agradeço muito a Deus por me dar essas 4 pessoas.

Paula Ragusa, só Deus sabe o quanto te dedico essa Tese, do início ao fim. Te amo e sei que está e estará ao meu lado sempre, minha paz, minha vida. 


\section{AGRADECIMENTOS}

À Deus, primeiramente, que me guia desde os princípios da minha vida.

Ao meu orientador Prof. Dr. Cássio Edvard Sverzut, por me aceitar como orientado e pela confiança em mim depositada para realização deste trabalho.

Aos professores da FOP Unicamp: Alexander Tadeu Sverzut e Márcio de Moraes, por me introduzir ao mundo virtual do Dolphin.

À Equipe do CTI Renato Archer pela ajuda nos passos iniciais dessa Tese.

Aos Professores do doutorado: Dr. Márcio Mateus Beloti, Dr. Samuel Porfírio Xavier, Dr. Alexandre Elias Trivellato, Dr. Luiz Antônio Salata, Dr. Paulo Tambasco de Oliveira, Dr. Valdemar Mallet da Rocha Barros e Dr. Adalberto Luiz Rosa por todo aprendizado durante as disciplinas.

Aos Profs. Dr. Alexandre Elias Trivellato e Dra. Mírian Aiko Nakane Matsumoto pela aceitação na banca de qualificação e palavras de apoio ao desenvolvimento deste trabalho.

Ao Prof. Dr. Wilton Mitsunari Takeshita, que tive o prazer de conhecer quando ambos morávamos em Maringá, pela imensa ajuda e orientação durante este trabalho.

À minha amiga querida Rosangela Aparecida Ferezin, companheira de clínica. 
Às funcionárias e ex funcionárias do Departamento de Cirurgia e Traumatologia Buco-Maxilo-Facial e Periodontia: Tatiana Angeli Passos Fernandes, Aparecida Dulce de Oliveira Negreti e Carla Daniela Lima da Silva e Maria Isabel Gobbo Simonetti, por todo auxílio e atenção.

Aos colegas do doutorado: Felipe Perraro, Emanuela Prado Ferraz, Gileade Pereira Freitas, Helena Bacha Lopes e Evandro Carneiro pelos bons momentos compartilhados durante estes anos de doutorado.

Aos amigos Patrick Osborne e Rafael Tajra, pelo companheirismo e conversas infindáveis.

Aos amigos da clínica PAE Juliana Rozatto, Pedro Henrique Carvalho e Soraya Oliveira.

À Coordenação de Aperfeiçoamento de Pessoal de Nível Superior, pela concessão da bolsa de doutorado.

$E$ a todos que fizeram parte do meu desenvolvimento pessoal e profissional durante a realização deste trabalho e que não foram citados. 
O encontro da preparação com a oportunidade gera o rebento que chamamos sorte. 


\section{RESUMO}

Dias RR. Análise linear do septo nasal em pacientes submetidos a expansão rápida de maxila assistida cirurgicamente [tese]. Ribeirão Preto: Universidade de São Paulo, Faculdade de Odontologia de Ribeirão Preto, 2018. 69p.

A expansão rápida de maxila assistida cirurgicamente (ERMAC) é um procedimento cirúrgico amplamente utilizado para resolução de alterações oclusais transversais de maxila em pacientes com maturidade óssea. No entanto, as alterações morfológicas que ocorrem após a utilização desta técnica ainda dispõem de poucos estudos na literatura, principalmente no que diz respeito à cavidade nasal em sua porção inferior e ao posicionamento do septo nasal em imagens tridimensionais. Desta forma, o presente estudo propôs-se a acessar medidas lineares do septo nasal de pacientes adultos que realizaram ERMAC no período de 2009 a 2013, em uma análise retrospectiva de tomografias computadorizadas de feixe cônico (TCFCs). Arquivos DICOM foram analisados no programa Dolphin Imaging ${ }^{\circledR}$, com o objetivo de identificar alterações no posicionamento do septo nasal em três momentos do tratamento: pré-cirúrgico, pós-cirúrgico imediatamente após o travamento do disjuntor e pós-cirúrgico tardio. As análises foram realizadas a partir de 4 pontos em septo nasal equidistantes em posição anteroposterior e em altura, utilizando referências fixas do crânio, para medidas laterais de deslocamento. A amostra final foi composta por 26 pacientes, com média de idade de 30,58 anos. Avaliando as medidas pré, pós-operatória imediata e tardia, nenhuma diferença significativa foi encontrada entre os tempos, nas quatro medidas fixas de septo nasal, aplicando o teste de ANOVA com nível de significância de $5 \%$. Comparando também os tempos isoladamente, não houve diferença estatisticamente significativa entre os lados direito e esquerdo, aplicando-se o teste t de Student, o que também evidenciou uma simetria no septo nasal. As medidas do septo nasal não sofreram alterações nos diferentes tempos cirúrgicos em toda a sua extensão inferior, e se mantiveram simétricas durante todo o período de acompanhamento dos pacientes.

Palavras-chave: Técnica de Expansão Palatina; Septo Nasal; Tomografia Computadorizada de Feixe Cônico; Cirurgia Bucal. 


\begin{abstract}
Dias, RR. Linear analysis of the nasal septum in patients submitted to surgically assisted rapid maxillary expansion [thesis]. Ribeirão Preto: University of São Paulo, School of Dentistry of Ribeirão Preto, 2018. 69p.

The surgically assisted rapid maxillary expansion (SARME) is a widely used surgical procedure for the resolution of transverse maxillary occlusal changes in patients with bone maturity. However, the morphological alterations that occur after the use of this technique still have few studies in the literature, mainly regarding the nasal cavity in its inferior portion and the positioning of the nasal septum in three-dimensional images. Thus, the present study proposed to access linear nasal septum measurements of adult patients who underwent SARME from 2009 to 2013, in a retrospective analysis of cone beam computed tomographies (CBCTs), in DICOM files, through Dolphin Imaging® program, aimed to identify significant changes during three moments of the treatment: pre-operative, postoperative immediately after the palatal expansion device locking and late postoperative. The analyzes were performed from 4 points in the nasal septum, equidistant in anteroposterior position and in height, using fixed cranial references, for lateral measures of displacement. The final sample consisted of 26 patients, with a mean age of 30.58 years. Evaluating the pre, immediate and late postoperative measurements, no significant difference was found between the times in the four fixed nasal septum measurements, applying the ANOVA test with significance level of $5 \%$. Comparing the times alone, there was no statistically significant difference between the right and left sides, applying Student's $t$ test, which also showed a symmetry in the nasal septum. The measurements of the nasal septum did not change in the different surgical times throughout their inferior extension, and they remained symmetrical throughout the period of follow-up of the patients.
\end{abstract}

Key words: Palatal Expansion Technique; Nasal Septum; Cone-Beam Computed Tomography; Surgery, Oral. 


\section{LISTA DE FIGURAS}

Figura 1. Aparelho de Hyrax em início de ativação.

Figura 2. Osteotomia realizada no lado direito em porção lateral da maxila envolvendo os pilares zigomaticomaxilar e nasomaxilar

Figura 3. Osteotomia realizada no lado esquerdo em porção lateral da maxila envolvendo os pilares zigomaticomaxilar e nasomaxilar.

32

Figura 4. Posicionamento do cinzel de Sverzut em região anterior de maxila para obtenção da fratura em linha média maxilar

Figura 5. Sutura em região de fundo de sulco maxilar

Figura 6. Aparelho de Hyrax travado com resina após expansão desejada...

Figura 7. Padronização da cabeça conforme o plano coronal (z) Margem infraorbitária

Figura 8. Padronização da cabeça conforme o plano axial (x) - Forame espinhoso bilateralmente.

Figura 9. Padronização da cabeça conforme o plano sagital (y) - Plano horizontal de Frankfurt).

Figura 10. Corte coronal em TCFC. Ponto LM, situado na metade da distância entre forames espinhosos em janela coronal.

Figura 11. Corte sagital em TCFC. Pontos de referência em maxila (P2, P3, P4 e ENP), distância da linha de referência LM até a altura maxilar LMP e a distância de LMP até a ENP.

Figura 12. Corte axial em TCFC. Os quatro pontos de referência da divisão maxilar foram então ajustados para ficarem exatamente em região central do septo nasal..

Figura 13. Corte coronal em TCFC. Referência da altura do arco zigomático, neste caso acima da referência LM. Neste ponto (LMZ), em janela axial, visualizamos por completo o arco zigomático, bilateralmente. 
Figura 14. Corte sagital em TCFC. Pontos de referência da altura do arco zigomático (P2', P3', P4' e ENP') projetados a partir dos pontos de referência maxilares (P2, P3, P4 e ENP), já centralizados em septo nasal.

Figura 15. Janela axial em TCFC. Pontos de referência na altura do arco zigomático (P2', P3', P4' e ENP') foram medidos bilateralmente até a borda externa do arco zigomático, em

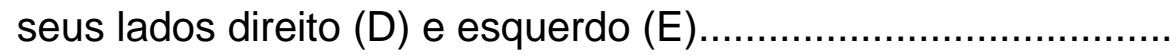

Figura 16. Gráfico de médias $(\mathrm{mm})$ e desvio padrão para os diferentes tempos (pré, pós imediato e pós tardio), aplicando o ANOVA, com nível de significância de 5\%, como não houve diferença significativa, não foi aplicado o pós-teste de Tukey.

Figura 17. Gráfico de médias $(\mathrm{mm})$ e desvio padrão para o pré-operatório comparando os lados direito e esquerdo, aplicando o teste $t$ para variáveis independentes. *Diferença estatisticamente significativa $(p<0.05)$

Figura 18. Gráfico de médias $(\mathrm{mm})$ e desvio padrão para o pósoperatório imediato comparando os lados direito e esquerdo, aplicando o teste t para variáveis independentes. *Diferença

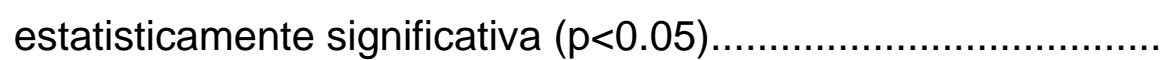

Figura 19. Gráfico de médias $(\mathrm{mm})$ e desvio padrão para o pósoperatório tardio comparando os lados direito e esquerdo, aplicando o teste t para variáveis independentes. *Diferença estatisticamente significativa $(p<0.05)$ 


\section{LISTA DE TABELAS}

Tabela 1. Média $(\mathrm{mm})$ e ANOVA para as diferentes medidas em diferentes tempos. 


\section{SUMÁRIO}

1 INTRODUÇÃO

2 OBJETIVO

3 MATERIAL E MÉTODOS

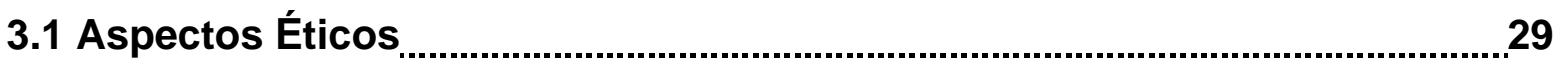

3.2 Caracterização e População do Estudo …………………………………….......2

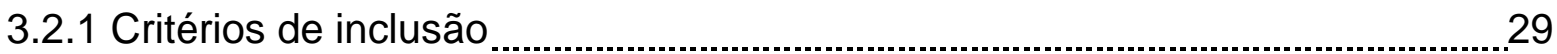

3.2.2 Critérios de exclusão

3.3 Protocolo de Pesquisa

3.3.1 Instalação do aparelho ortodôntico-cirúrgico após diagnóstico …………..........30

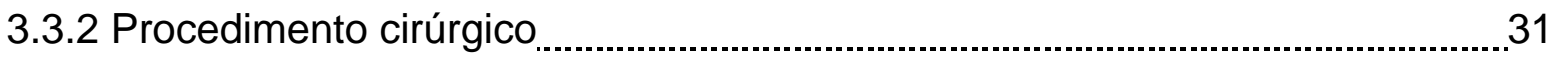

3.3.3 Medidas pós cirúrgicas de ativação do aparelho de Hyrax ..........................33

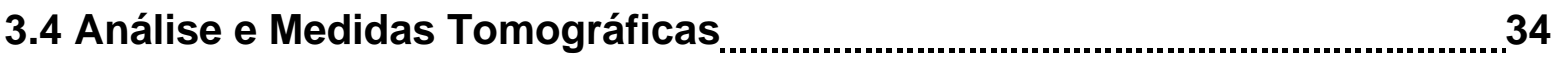

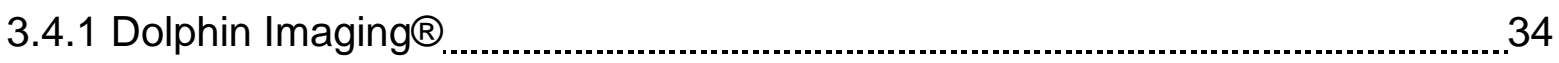

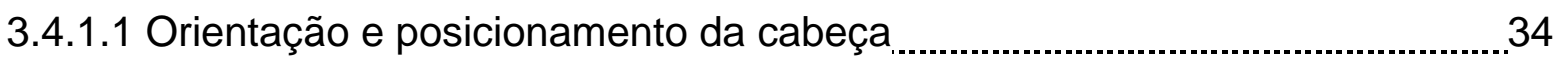

3.4.1.2 Medidas lineares

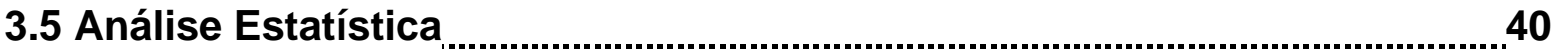

4 RESULTADOS

5 DISCUSSÃO

6 CONCLUSÕES

REFERÊNCIAS 
APÊNDICES

ANEXO 
1 INTRODUÇÃO 



\section{INTRODUÇÃO}

A expansão de maxila é uma técnica utilizada para corrigir arcos maxilares atrésicos e mordida cruzada através de um processo de abertura dos ossos do palato em maxila. Este processo de abertura óssea trata-se de uma distração osteogênica, proposta originalmente por Alessandro Codivilla, em 1905 (Codivilla, 1994). Contudo, mesmo antes do conhecimento da técnica de distração osteogênica, a mesma foi utilizada e relatada pela primeira vez em ossos maxilares por Angell em 1860 (Angell, 1860), quando uma garota de aproximadamente 14 anos teve sua sequência de erupção e alinhamento dentário em maxila prejudicados devido à um primeiro molar esquerdo cariado e um canino vestibularizado e fora do arco. Após a extração do molar, um dispositivo oblíquo foi instalado para expandir o espaço entre os pré-molares direito e esquerdo horizontalmente e, feito isso, um espaço entre incisivos foi notado, relatando-se que uma possível movimentação óssea horizontal fora obtida. Entretanto, apesar deste relato, somente em 1961 a técnica foi popularizada por Haas (Haas, 1961), comprovando a eficácia do método de expansão maxilar em modelo animal por meio de um dispositivo dento-mucosuportado, chamado futuramente de disjuntor de Haas, e posteriormente aplicado pelo mesmo autor em humanos, como uma força ortopédica funcional. Este mesmo autor notou que além da resolução ortodôntica dos casos de mordida cruzada, havia uma melhora significativa respiratória devido ao aumento de volume da fossa nasal.

O septo nasal é formado por uma cartilagem, pelo osso vômer na região inferior e pela placa perpendicular do osso etmoidal na porção superior e posterior. Por estar inserido inferiormente nos ossos maxilares, está vulnerável às forças aplicadas na região (Mortellaro et al., 2010; Hur et al., 2016).

Deste modo, o deslocamento do septo nasal e de suas inserções ósseas e cartilaginosas, bem como as consequências que isso poderia acarretar, é uma preocupação persistente desde os primórdios da técnica. Baseado em outros estudos, Haas, no artigo de 1961, cita que o deslocamento horizontal da maxila retifica o septo nasal em algumas situações, sendo uma das teorias o reajuste do plano maxilar, que com a inclinação dos incisivos para a vestibular devido à forças axiais, o septo ganharia espaço e entraria em uma posição mais retilínea devido ao abaixamento do processo palatino da maxila (Black, 1909). Outra teoria proposta na época diz respeito ao deslocamento lateral dos ossos maxilares e o espaço criado 
entre os mesmos na região central, que proporcionaria um melhor posicionamento do processo palatino da maxila e, assim, uma retificação do septo originalmente desviado (Brown, 1903). No entanto, estas teorias sobre as consequências inerentes ao septo nasal basearam-se apenas em achados clínicos observacionais e imaginológicos em duas dimensões.

Até aquele momento da história, contudo, a expansão de maxila se destinava apenas a pacientes jovens, com imaturidade esquelética, onde somente forças ortopédicas seriam suficientes para causar a expansão do palato, que ainda não se encontra fusionado em sua porção central óssea. Se estas mesmas forças fossem aplicadas a indivíduos adultos, problemas como a falha no dispositivo e na expansão dos ossos maxilares, dores intensas durante ativação, necrose por pressão do próprio dispositivo devido à forças extremas, resultados instáveis e inclinações dentárias excessivas ocorriam comumente (Bell e Epker, 1976; Graber e Vanarsdall, 1994; Menon et al., 2010).

Assim, a expansão cirúrgica de maxila, descrita originalmente por Brown em seu livro do ano de 1938 (Brown, 1938), ofereceu uma nova perspectiva com relação ao procedimento, propondo que a linha de força em região central de maxila fosse osteotomizada, permitindo que o palato se deslocasse lateralmente. Esta técnica cirúrgica foi futuramente aperfeiçoada por alguns autores, por meio de osteotomias em outros pilares de força maxilar, como pilares zigomático-maxilares, septo nasal, processos pterigopalatinos e região de pilares nasais laterais, com o intuito de facilitar a expansão da maxila e tornar este movimento mais previsível, sendo a técnica proposta por Bell e Epker (1976) uma das mais comuns.

Atualmente, a técnica é conhecida como expansão rápida de maxila assistida cirurgicamente (ERMAC) e tornou-se um procedimento amplamente utilizado, principalmente para resolução de alterações oclusais transversais maxilomandibulares em pacientes que já apresentem maturidade óssea, o que impede que apenas forças ortopédicas expandam o arco maxilar (Han et al., 2009). A indicação da ERMAC não se limita apenas à problemas transversais de maxila, mas secundariamente também é utilizada para auxiliar nas deficiências respiratórias associadas ao estreitamento das vias aéreas superiores, pois promove a separação dos ossos maxilares em uma forma piramidal, cuja expansão máxima da base ocorre na porção maxilar anterior, ao nível dos dentes incisivos, o que é visto principalmente em procedimentos de ERMAC onde não se solta a placa do processo 
pterigoide (Klapper e George, 1995; Chamberland e Proffit, 2008). O aumento total do volume da cavidade nasal causado pela expansão auxilia na melhora da capacidade respiratória (Oliveira De Felippe et al., 2008; Deeb et al., 2010). No entanto, um estudo mais recente mostrou que a expansão maxilar não resultou estatisticamente em aumento das dimensões nas vias aéreas superiores (PereiraFilho et al., 2014).

De acordo com o estudo de Menon em 2010 (Menon et al., 2010), as indicações para a realização da ERMAC incluem deficiência transversa de maxila maior que $5 \mathrm{~mm}$, discrepância significativa entre maxila e mandíbula em largura, falha prévia na expansão ortopédica e/ou ortodôntica, necessidade de expansão maxilar maior do que $7 \mathrm{~mm}$, o que torna a cirurgia Le Fort I instável devido à elasticidade do palato, que permite em torno de $6 \mathrm{~mm}$ de expansão (Betts, 2016), recessão dentária significativa em região de pré-molares e caninos, e pacientes com mais de 15 anos de idade, devido à maturidade óssea.

Com a popularização da ERMAC ao longo dos anos, outros estudos foram necessários para diminuir o índice de complicações inerentes à técnica, sendo uma das mais críticas relacionada à instabilidade pós-cirúrgica. Proffit et al. (1996), e posteriormente em uma revisão em 2007, compararam os movimentos cirúrgicos ósseos em cirurgia ortognática e sua estabilidade, identificando que a expansão horizontal da maxila com osteotomias segmentares tem alta recidiva dentária, chegando a $3 \mathrm{~mm}$ em região de primeiros molares, o que se assemelha a estudos que comparam este movimento e a ERMAC, que tem recidiva de cerca de 28 a $36 \%$, na mesma região (Byloff e Mossaz, 2004; Chamberland e Proffit, 2008). Após o ponto de máxima expansão, cerca de metade da distância obtida em largura do arco é às custas da expansão óssea, e a outra metade por inclinação dentária (Chamberland e Proffit, 2008).

Estudos comprovam, no entanto, que a recidiva é basicamente atribuída ao retorno dentário e sua inclinação, principalmente em região posterior de maxila, e não à recidiva óssea. Sendo assim, uma expansão maior do que a desejada deve ser obtida quando se utilizam aparelhos dento-suportados. (Proffit et al., 2007; Chamberland e Proffit, 2008). Em casos críticos, o tempo de reparo da região maxilar e estabilização do quadro, segundo alguns autores, levaria um tempo longo, chegando a 6 a 12 meses com o dispositivo em posição para reparo total da sutura palatina (Betts, 2016). Para diminuir os casos de recidiva dentária, foram 
desenvolvidos em 1999 dispositivos apoiados somente em tábua óssea maxilar, em região de palato, como uma alternativa às sobrecorreções ósseas-dentárias, que se tornaram dispensáveis com este dispositivo, além de diminuir o tempo de espera até a consolidação maxilar (Mommaerts, 1999).

Outra dúvida existente na literatura desde os primórdios da aplicação da ERMAC, como já questionado por Haas em 1961 (Haas, 1961) durante o estudo da técnica da expansão não cirúrgica da maxila, é referente ao deslocamento cirúrgico trans e pós-operatório do septo nasal. O desvio do septo nasal é associado muitas vezes à dificuldades respiratórias, comuns em maxilas atrésicas, e a retificação do mesmo seria importante após uma expansão cirurgicamente assistida (Betts et al., 1995; Woods et al., 1997; Betts, 2016). Alguns autores inclusive propõem a ERMAC com osteotomia em base de septo nasal, em sua inserção na maxila, justificando que há possibilidade de desvio do mesmo, deslocamento lateral ou alteração das vias aéreas nasais durante a fase de distração se a mesma não for realizada (Betts et al., 1995; Betts, 2016).

À despeito da importância do posicionamento do septo nasal no pós operatório, existem poucos artigos na literatura que estudaram as alterações em septo nasal após o procedimento de ERMAC, dos quais a maioria aborda as posições e mudanças apenas através de exames clínicos ou de imagem bidimensionais (Angell, 1860; Chamberland e Proffit, 2008; Altug-Atac et al., 2010; Gurgel et al., 2014). Com os avanços tecnológicos e popularização dos exames de imagem, como a tomografia computadorizada de feixe cônico (TCFC), uma investigação mais precisa se torna possível e necessária para sanar dúvidas cirúrgicas.

Devido à escassez de estudos referentes ao posicionamento do septo nasal após a ERMAC, há uma falta de consenso na literatura quanto à necessidade ou não de se fazer a osteotomia da base do septo para evitar o seu desvio. Considerando que esta osteotomia aumenta a morbidade pós operatória (Politis, 2012), faz-se necessário identificar se tal técnica é fundamental para a preservação da posição do septo.

Diante do exposto, o presente trabalho propôs-se a comparar a posição do septo nasal antes da ERMAC e no pós-operatório imediato e tardio, através de sua mensuração em diversas janelas tomográficas de TCFC, em pacientes que foram submetidos a ERMAC sem osteotomia do septo nasal, com o objetivo de verificar se houveram alterações significativas. 
2 OBJETIVOS 



\section{OBJETIVOS}

- Acessar medidas lineares do septo nasal de pacientes adultos submetidos a ERMAC através da análise retrospectiva de TCFCs;

- Comparar as medidas do septo entre os tempos pré-cirúrgico, póscirúrgico imediato e pós-cirúrgico tardio. 

3 Material e métodos 



\section{MATERIAL E MÉTODOS}

\subsection{Aspectos Éticos}

O presente projeto de pesquisa foi aprovado pelo Comitê de Ética em Pesquisa em Seres Humanos da Faculdade de Odontologia de Ribeirão Preto, Universidade de São Paulo - FORP/USP, sob número CAAE: 56389416.0.0000.5419.

\subsection{Caracterização e População do Estudo}

Trata-se de um estudo do tipo epidemiológico individual, observacional e longitudinal (retrospectivo), que avaliou prontuários e tomografias computadorizadas de feixe cônico (TCFC) de pacientes submetidos a expansão rápida de maxila assistida cirurgicamente (ERMAC). As mensurações tomográficas foram avaliadas em três diferentes momentos do tratamento, conforme abaixo, e posteriormente correlacionadas:

- Momento 1: Pré-cirúrgico;

- Momento 2: Pós-cirúrgico (após travamento do aparelho Hyrax);

- Momento 3: Pós-cirúrgico tardio (6 meses após o travamento do aparelho Hyrax, mantendo o mesmo em posição).

\subsubsection{Critérios de Inclusão}

Foram incluídos na pesquisa os prontuários de todos os pacientes submetidos a ERMAC sob anestesia geral no Hospital Estadual de Ribeirão Preto, pelo serviço de Residência em Cirurgia e Traumatologia Buco-Maxilo-Faciais da Faculdade de Odontologia de Ribeirão Preto da Universidade de São Paulo, através do Sistema Único de Saúde, no período de 2009 a 2013.

\subsubsection{Critérios de Não Inclusão}

Não foram incluídos na amostra: os pacientes que não realizaram as TCFC no tempo correto da pesquisa; pacientes que não respeitaram o protocolo pré e pósoperatório (uso da medicação, dieta, etc); pacientes que abandonaram o tratamento por quaisquer motivos; pacientes com histórico de cirurgia em septo nasal; pacientes que utilizaram medicamentos com interferência no metabolismo ósseo (corticoides por longo prazo, bisfosfonatos, etc); pacientes que foram submetidos a uma nova 
intervenção cirúrgica no mesmo local; pacientes cujo aparelho disjuntor Hyrax utilizado para expansão tenha apresentado algum problema durante o período de acompanhamento ou ativação; e pacientes portadores de alguma síndrome, que de alguma forma pudesse interferir com os resultados da pesquisa.

\subsection{Protocolo de Pesquisa}

Todos os pacientes submetidos à ERMAC seguiram um protocolo de atendimento da equipe da Residência em Cirurgia e Traumatologia Buco-MaxiloFaciais da Faculdade de Odontologia de Ribeirão Preto, Universidade de São Paulo - FORP/USP (APÊNDICE A) e foram encaminhados ao ortodontista para cumprimento do protocolo ortodôntico do tratamento (APÊNDICE B). Além disso, todos foram submetidos à TCFC utilizando um tomógrafo do modelo iCat ${ }^{\circledR}$ Classic (Imaging Sciences International, Hatfield, Estados Unidos da América), com fatores de exposição de $120 \mathrm{KV}$ e $36,12 \mathrm{mAs}$ em 0,25mm de intervalo de reconstrução e de espessura de corte. Os períodos para obtenção da TCFC foram no pré-operatório, pós-operatório à cirurgia de ERMAC (após travamento do aparelho Hyrax) e pósoperatório tardio (6 meses após travamento do aparelho Hyrax). As imagens foram salvas em arquivo DICOM (Digital Imaging and Communication in Medicine).

\subsubsection{Instalação do aparelho ortodôntico-cirúrgico após diagnóstico}

O aparelho disjuntor Hyrax utilizado no protocolo foi aquele cujas bandas são posicionadas nos primeiros pré-molares e primeiros molares maxilares, bilateralmente. O aparelho teve extensão palatina de mesial de canino à distal de segundo molar, em ambos os lados, confeccionadas em fio de aço $0,8 \mathrm{~mm}$. $O$ aparelho ficou a uma distância mínima de $2 \mathrm{~mm}$ da mucosa palatina, de modo a evitar o contato do aparelho com a mucosa durante a ativação (Figura 1). 
Figura 1. Aparelho de Hyrax em início de ativação.

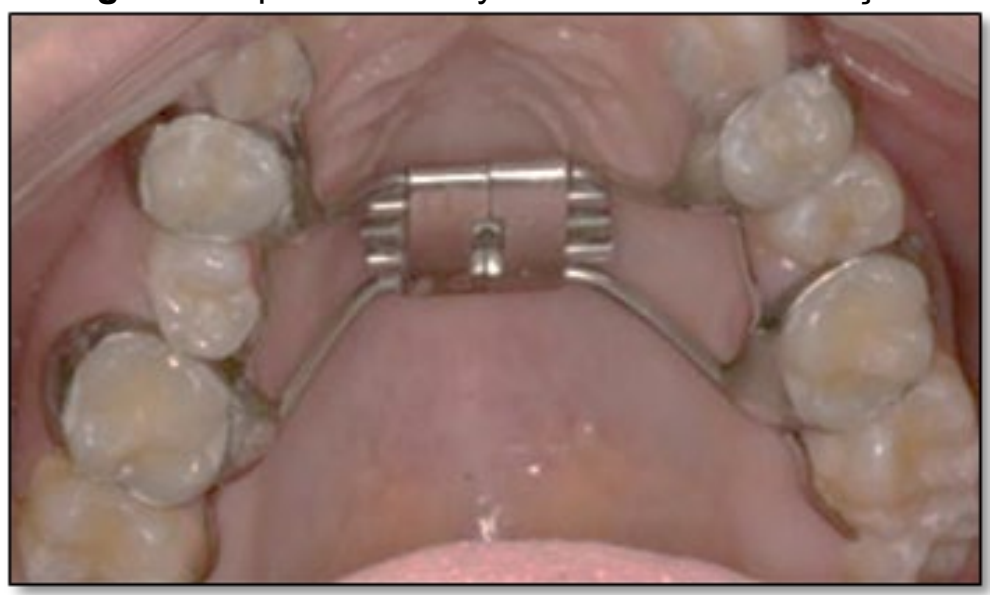

\subsubsection{Procedimento cirúrgico}

Os procedimentos cirúrgicos foram realizados sob anestesia geral no Hospital Estadual de Ribeirão Preto e pelo Sistema Único de Saúde (SUS). A ERMAC foi realizada administrando-se em momento pré-cirúrgico, $1 \mathrm{~g}$ de cefazolina para profilaxia antibiótica e $10 \mathrm{mg}$ de dexametasona, ambos por via intravenosa (IV). A antissepsia intra e extra oral foram feitas com polivinilpirrolidona iodo (PVPI) a 10\%. O anestésico lidocaína a $2 \%$ com epinefrina 1:200.000 foi infiltrado no fundo de sulco vestibular da maxila, bilateralmente, para auxílio da anestesia geral no que se tange à dor, e para controle de sangramento local.

A incisão foi então feita com aplicação do eletrodo monopolar com a ponteira dissectora tipo Colorado em fundo de sulco vestibular, da mesial do primeiro molar até a mesial do canino, bilateralmente. O descolamento mucoperiosteal expôs os pilares zigomaticomaxilares e nasomaxilares. Utilizando uma peça de mão de baixa rotação e uma broca cirúrgica 702, foi realizada uma osteotomia sob intensa irrigação salina através do pilar zigomaticomaxilar em parede lateral da maxila até a abertura piriforme nasal, em ambos os lados, de acordo com a técnica proposta por Bays e Greco (Bays, R. A. e Greco, J. M., 1992) (Figuras 2 e 3). Em conformidade com o protocolo cirúrgico da Residência em Cirurgia e Traumatologia Buco-MaxiloFaciais, não foram osteotomizadas as placas pterigóides e o septo nasal. Após procedimentos iniciais, uma incisão vertical foi realizada sobre o freio labial com uma lâmina cirúrgica $\mathrm{n}^{\circ} 15$, seguido por um descolamento dos tecidos moles restrito a essa topografia. Uma osteotomia mediana entre os incisivos centrais foi demarcada primeiramente por uma peça de mão de baixa rotação e uma broca cirúrgica 701, e então se finalizou a separação maxilar com o auxílio de cinzel de Sverzut e martelo 
(Figura 4). O expansor Hyrax foi então ativado 8 vezes e desativado 4 vezes, resultando em $1 \mathrm{~mm}$ de ativação. A ferida foi suturada com fio de sutura 4-0 à base de poliglactina-910 (Figura 5).

A prescrição medicamentosa foi por via oral e consistiu de cetoprofeno $100 \mathrm{mg}$ a cada 8 horas por 3 dias e $500 \mathrm{mg}$ de dipirona sódica a cada 6 horas, igualmente por 3 dias, em caso de dor. Somente 7 dias após o procedimento cirúrgico os pacientes receberam instruções para iniciarem a ativação do aparelho de Hyrax.

Figura 2. Osteotomia realizada no lado direito em porção lateral da maxila envolvendo os pilares zigomaticomaxilar e nasomaxilar.

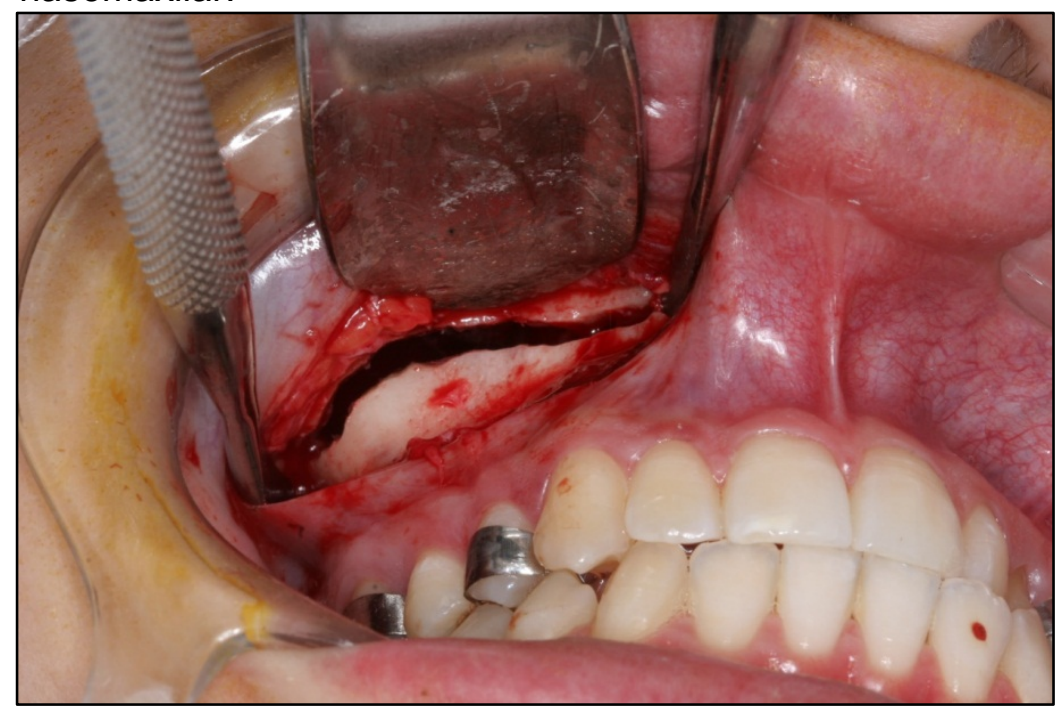

Figura 3. Osteotomia realizada no lado esquerdo em porção lateral da maxila envolvendo os pilares zigomaticomaxilar e nasomaxilar

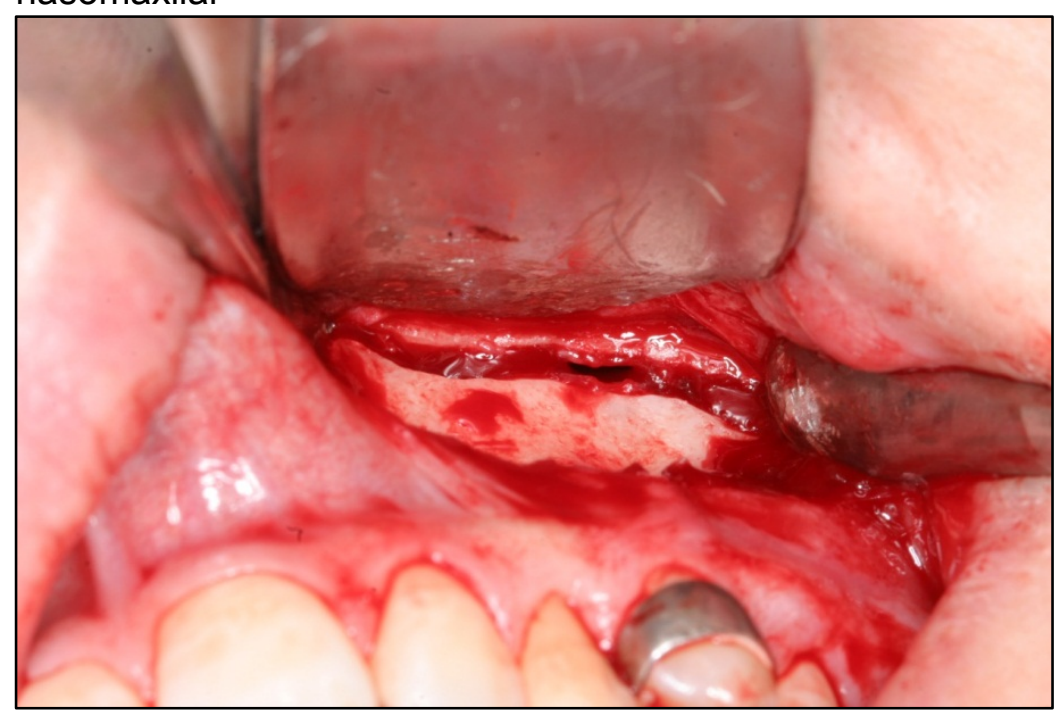


Figura 4. Posicionamento do cinzel de Sverzut em região anterior de maxila para obtenção da fratura em linha média maxilar.

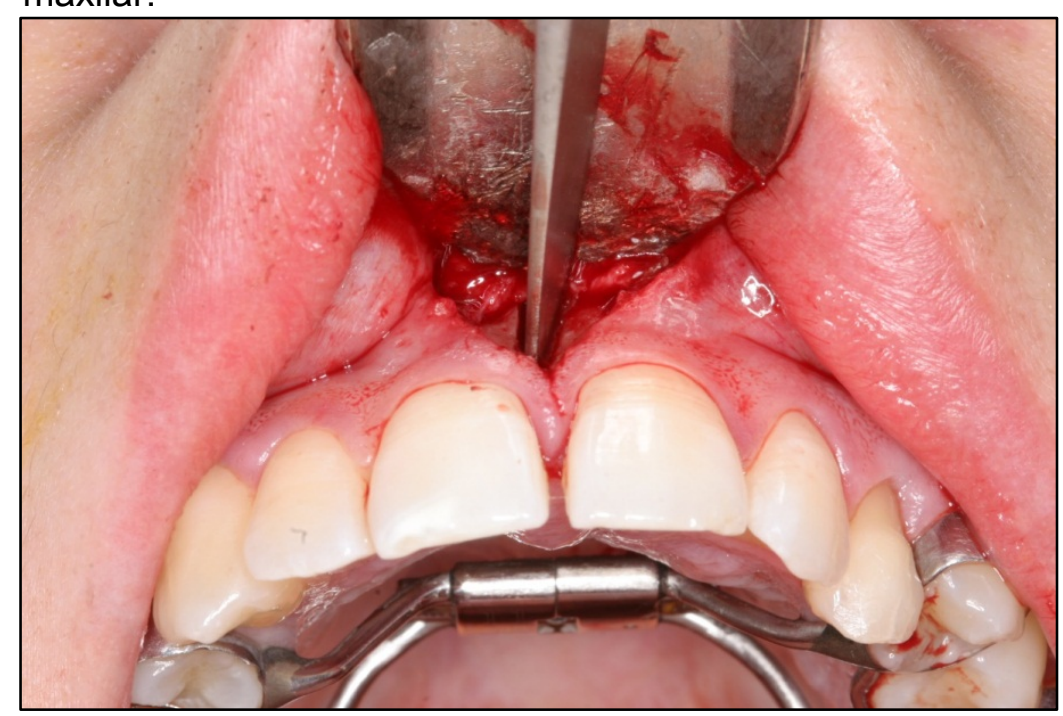

Figura 5. Sutura em região de fundo de sulco maxilar

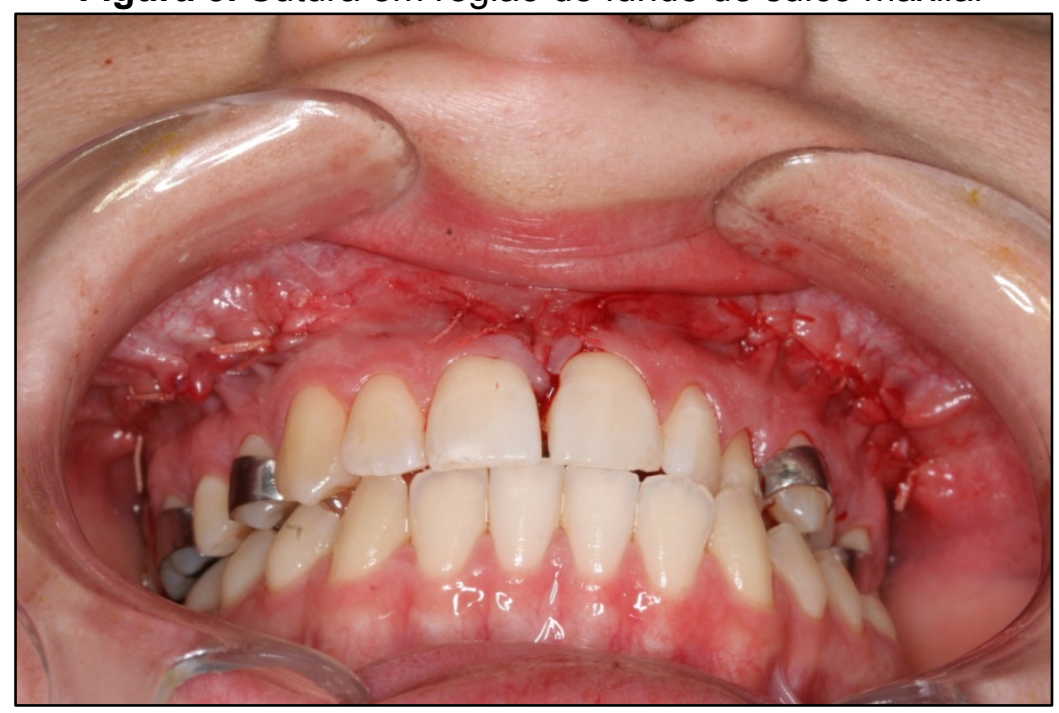

\subsubsection{Procedimentos pós cirúrgicos de ativação do aparelho de Hyrax}

Após um período de latência de 1 semana, foram indicadas 2 ativações (2/4 de volta) pela manhã e mais 2 ativações (2/4 de volta) à tarde, totalizando $1 \mathrm{~mm}$ de ativação do torno ao dia.

Após se obter a quantidade de sobrecorreção considerada pelo cirurgião responsável pelo caso e pelo ortodontista, o aparelho foi travado por 6 meses com fio de aço e resina acrílica quimicamente ativada, conforme demonstrado na figura 6 . 
Figura 6. Aparelho de Hyrax travado com resina após expansão desejada.

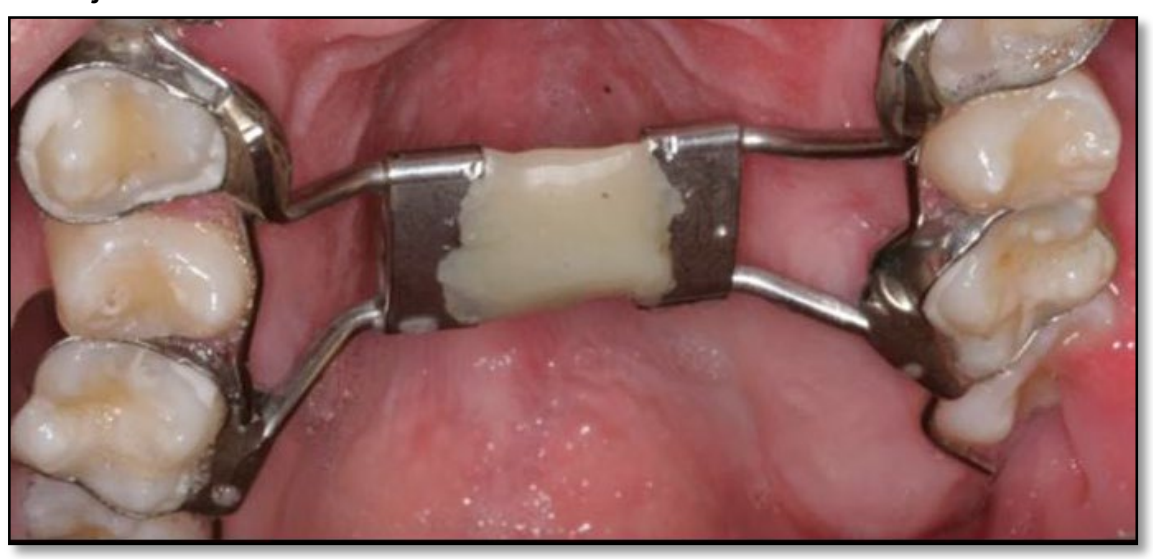

\subsection{Análise e Medidas Tomográficas}

As análises tomográficas lineares foram efetuadas no software Dolphin Imaging $^{\circledR}$ versão 11.9 (Dolphin Imaging and Management Solutions, Charsworth, CA, USA) conforme descrito a seguir.

\subsubsection{Dolphin Imaging ${ }^{\circledR}$}

\subsubsection{Orientação e posicionamento da cabeça}

Semelhante à pesquisas realizadas anteriormente por outros autores (Baratieri Cda et al., 2014; Lin et al., 2015), todas as tomografias foram padronizadas no plano coronal ( $z$ ) seguindo uma linha ligando a margem infraorbitária bilateralmente (Figura 7), no plano axial (x) com uma linha horizontal ligando os forames espinhosos bilateralmente alinhados (Figura 8), e no plano sagital $(y)$, estabelecido do ponto mais baixo da margem infraorbitária ao ponto mais alto da margem do meato acústico externo direito (plano horizontal de Frankfurt) (Figura 9). 
Figura 7. Padronização da cabeça conforme o plano coronal (z) - Margem infraorbitária.

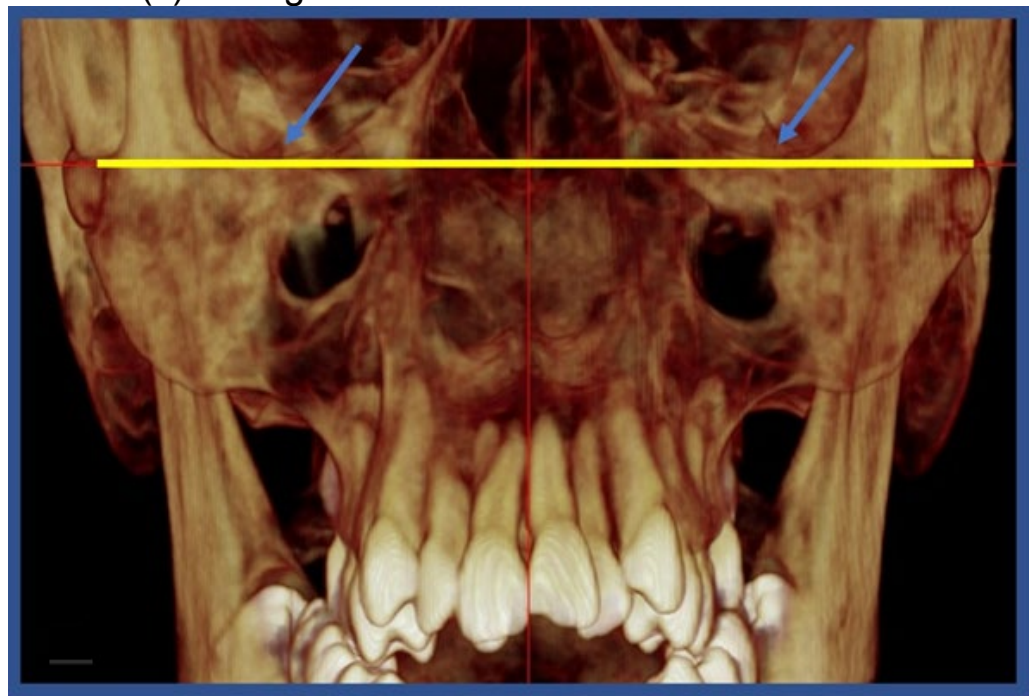

Figura 8. Padronização da cabeça conforme o plano axial (x) - Forame espinhoso bilateralmente.

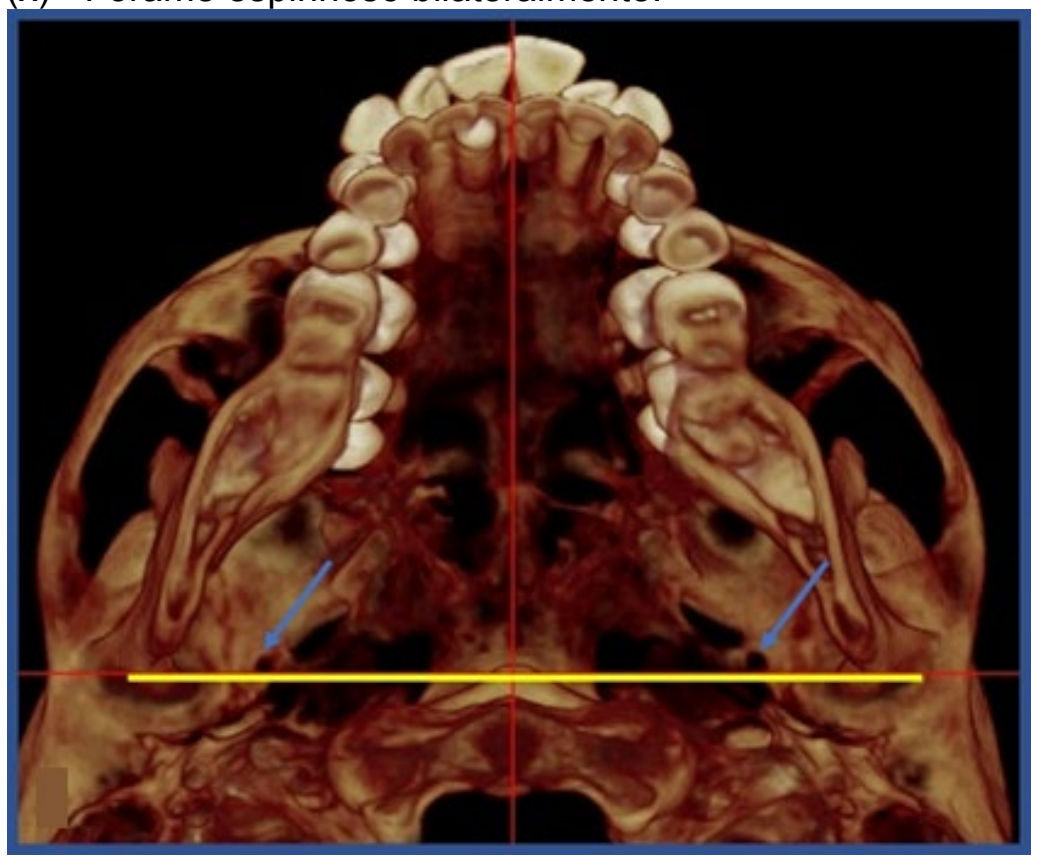


Figura 9. Padronização da cabeça conforme o plano sagital (y) - Plano horizontal de Frankfurt).

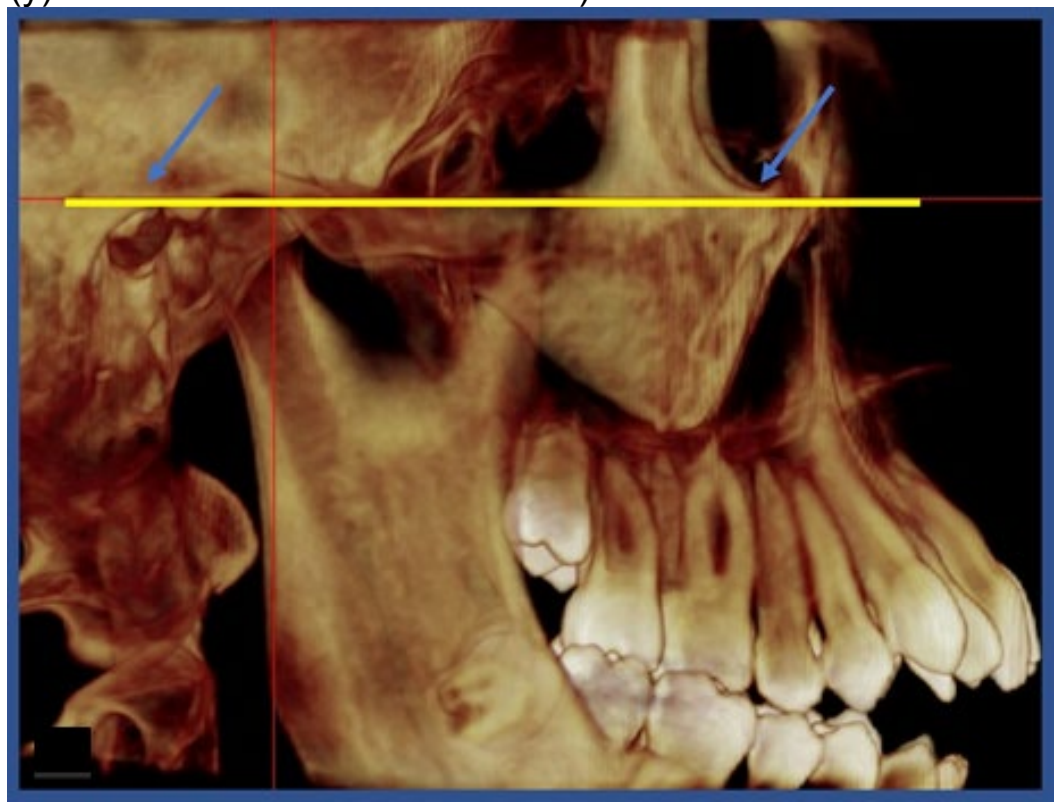

\subsubsection{Medidas lineares}

Todas as medidas lineares foram realizadas pelo mesmo avaliador, e uma calibração foi realizada em $20 \%$ dos casos.

Após o posicionamento do crânio ser padronizado, as medidas lineares foram então realizadas na primeira tomografia de cada caso, sendo esta a préoperatória, que serviu de referência para as pós-operatórias imediatas e tardias. No corte tomográfico bidimensional coronal, foram marcados pontos denominados "landmarks", no forame espinhoso da esquerda e da direita, e entre estes, exatamente na metade da distância, o primeiro ponto de referência denominado linha média ou LM (figura 10).

Figura 10. Corte coronal em TCFC. Ponto LM, situado na metade da distância entre forames espinhosos em janela coronal.

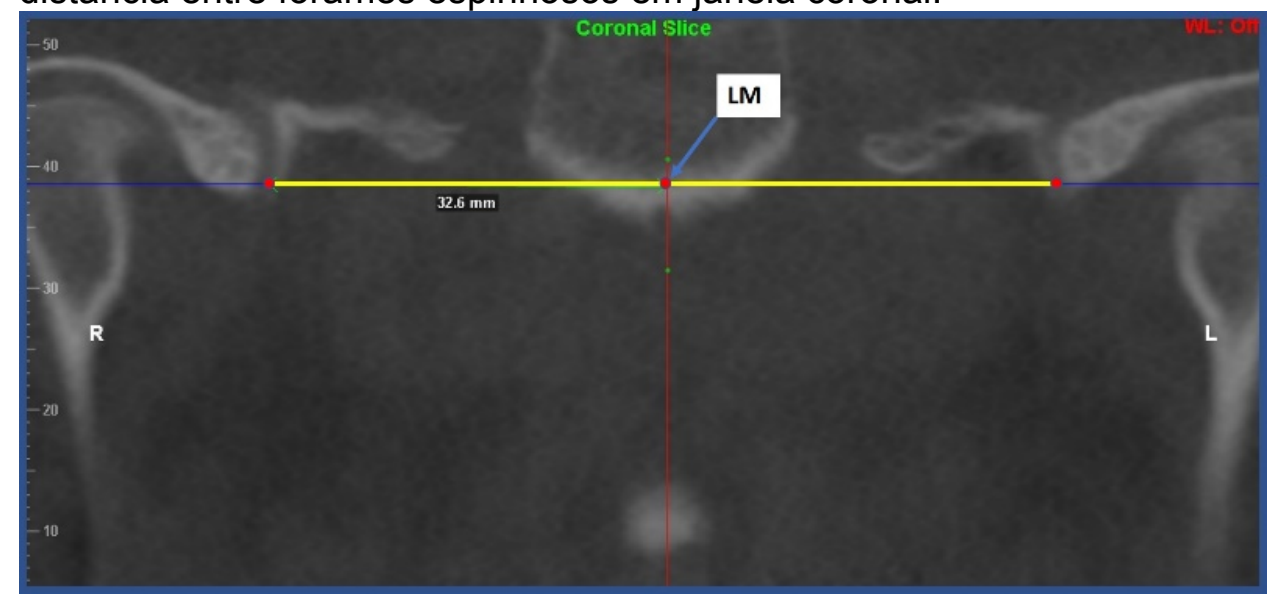


Então, na janela tomográfica sagital, no corte do ponto LM, foi traçada uma linha da espinha nasal posterior (ENP) até a espinha nasal anterior (ENA), que passasse pelo ponto mais alto da pré-maxila. O encontro da projeção horizontal posterior desta linha com a projeção vertical inferior do ponto LM foi denominada linha média posterior (LMP), e fornece a altura da maxila em relação ao ponto LM. Esta altura será fixa em todos os momentos tomográficos do mesmo paciente.

Ainda na janela sagital, a distância entre a ENA e a ENP foi dividida em 4 partes iguais, criando cinco pontos de referência. $O$ primeiro ponto de referência, exatamente na ENA, foi removido por se encontrar fora da área de fossa nasal, 0 que não justifica sua medida, e os 4 pontos restantes foram chamados de P2, P3, P4 e ENP. A medida do ponto LMP até a ENP também foi padronizada, para se tornar constante em todas as tomografias do mesmo paciente (figura 11).

Figura 11. Corte sagital em TCFC. Pontos de referência em maxila (P2, P3, P4 e ENP), distância da linha de referência LM até a altura maxilar LMP e a distância de LMP até a ENP.

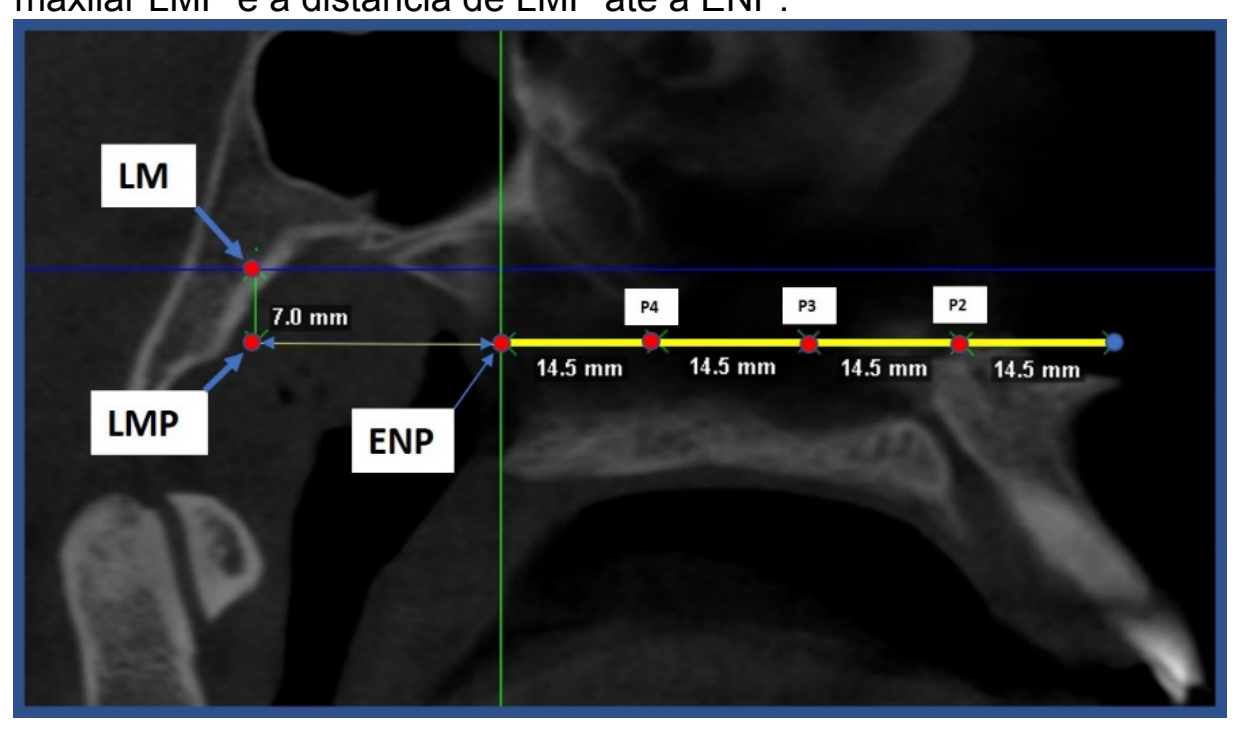

Em seguida, na janela tomográfica axial, os quatro pontos de divisão da maxila foram ajustados individualmente em região de septo nasal, para se situar exatamente em região central do septo em toda sua extensão conforme figura 12. 
Figura 12. Corte axial em TCFC. Os quatro pontos de referência da divisão maxilar foram então ajustados para ficarem exatamente em região central do septo nasal.

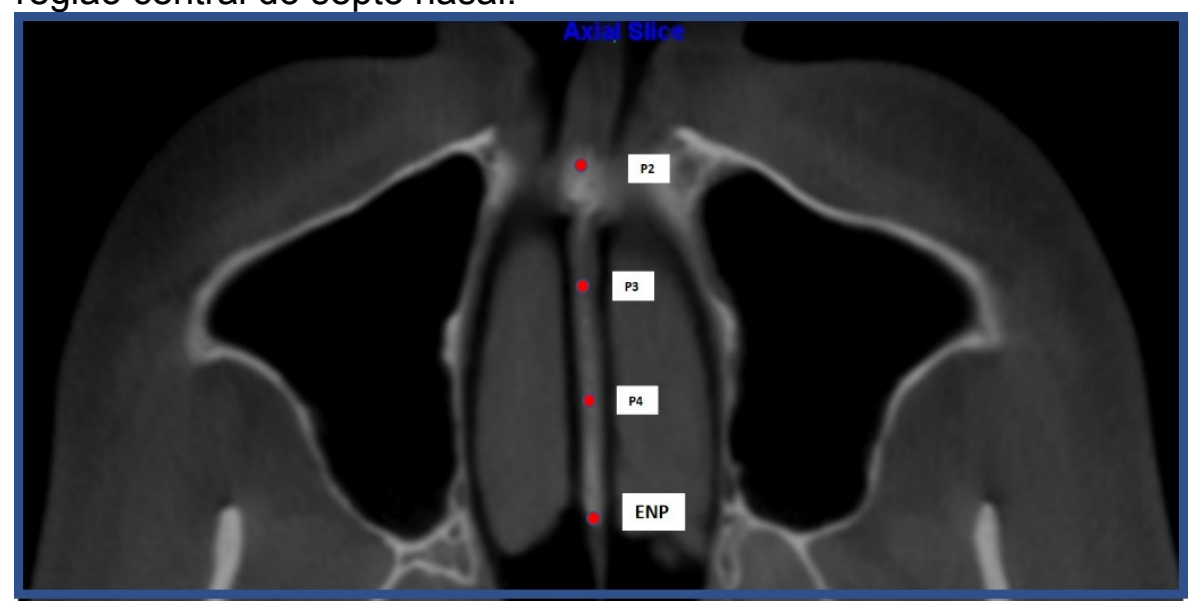

Seguindo-se as referências das janelas tomográficas coronal e axial, foi escolhida uma medida coincidente ou superior ao ponto LM, onde a visualização do arco zigomático bilateralmente fosse completa, permitindo usá-lo para projetar os pontos mais inferiores da maxila (P2, P3, P4 e ENP). Este ponto de referência foi denominado linha média no arco zigomático (LMZ), e este também foi padronizado em todas as tomografias subsequentes (figura 13).

Figura 13. Corte coronal em TCFC. Referência da altura do arco zigomático, neste caso acima da referência LM. Neste ponto (LMZ), em janela axial, visualizamos por completo o arco zigomático, bilateralmente.

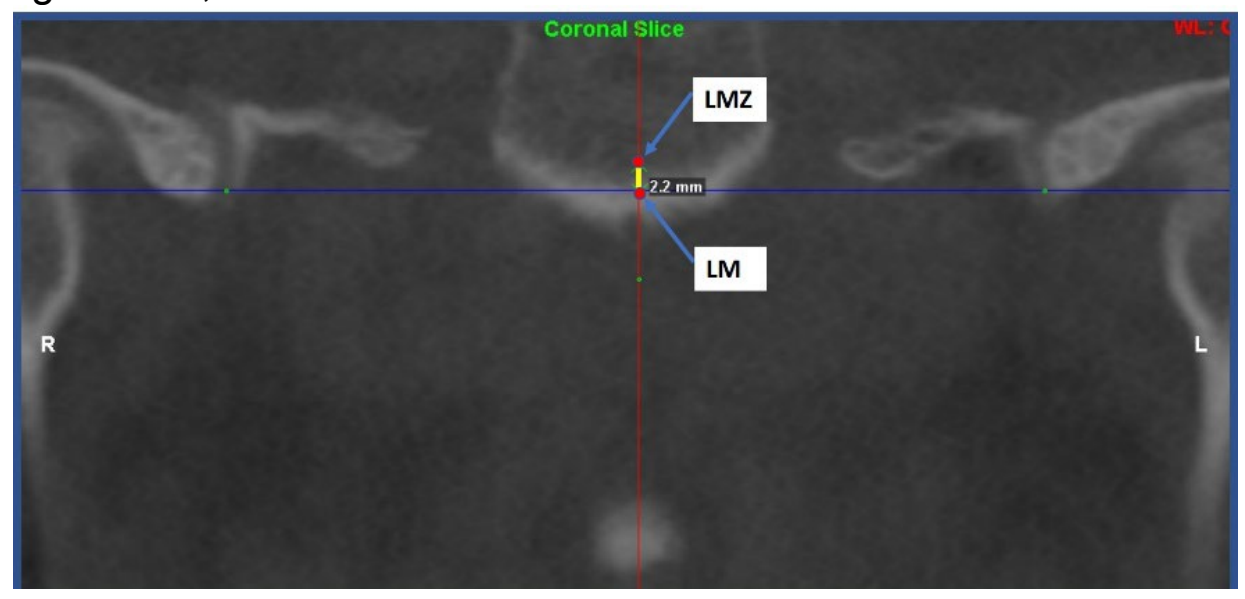

Em janela tomográfica sagital, tomando o ponto LMZ como referência de altura que permitiu ter o arco zigomático em toda sua extensão anteroposterior, foram marcados então pontos de referência, nesta altura, seguindo projeções dos quatro pontos maxilares medidos previamente, sendo eles P2, P3, P4 e ENP. Estes pontos respectivos denominaram-se P2', P3', P4' e ENP' (figura 14). 
Figura 14. Corte sagital em TCFC. Pontos de referência da altura do arco zigomático (P2', P3', P4' e ENP') projetados a partir dos pontos de referência maxilares ( $P 2, P 3, P 4$ e ENP), já centralizados em septo nasal.

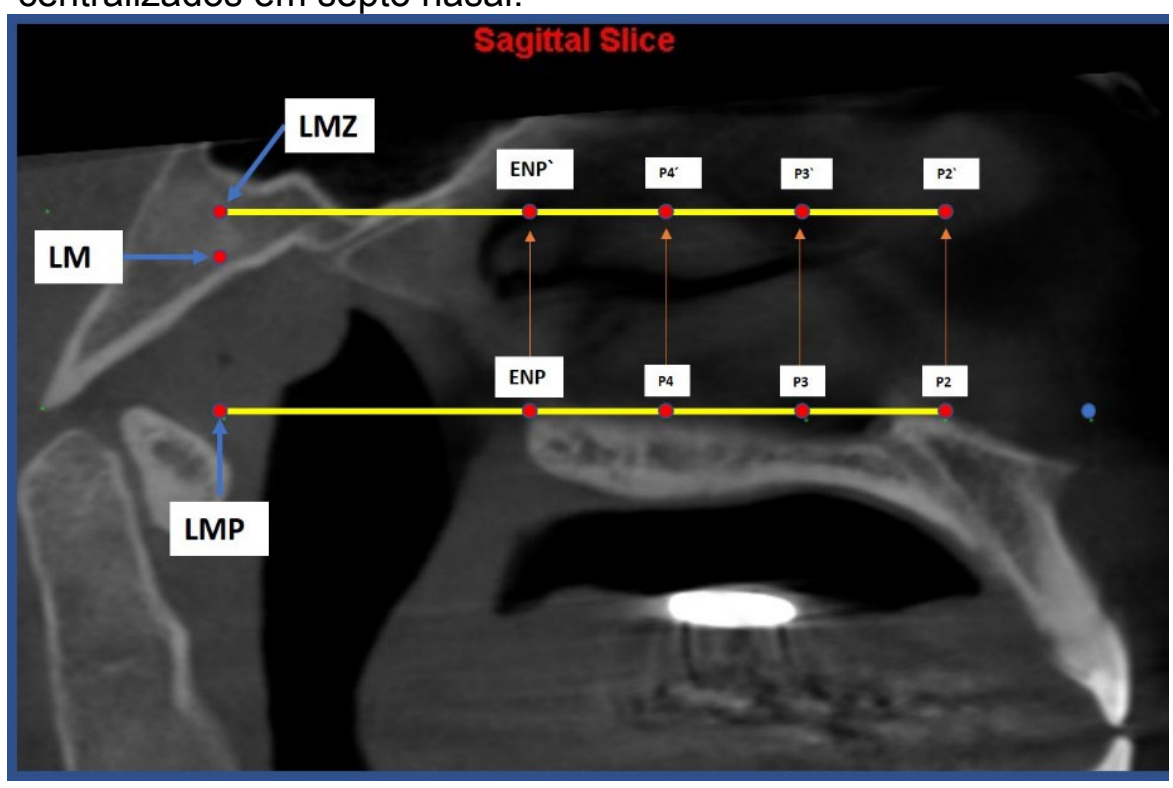

Por último, em janela tomográfica axial, foram feitas medidas na altura LMZ dos pontos de referência projetados P2', P3', P4' e ENP', até a parte externa do arco zigomático bilateralmente e estes dados adquiridos, sendo as do lado direito P2'D, P3'D, P4'D e ENP'D, e as do lado esquerdo P2'E, P3'E, P4'E e ENP'E (Figura 15).

Figura 15. Janela axial em TCFC. Pontos de referência na altura do arco zigomático (P2', P3', P4' e ENP') foram medidos bilateralmente até a borda externa do arco zigomático, em seus lados direito (D) e esquerdo (E).

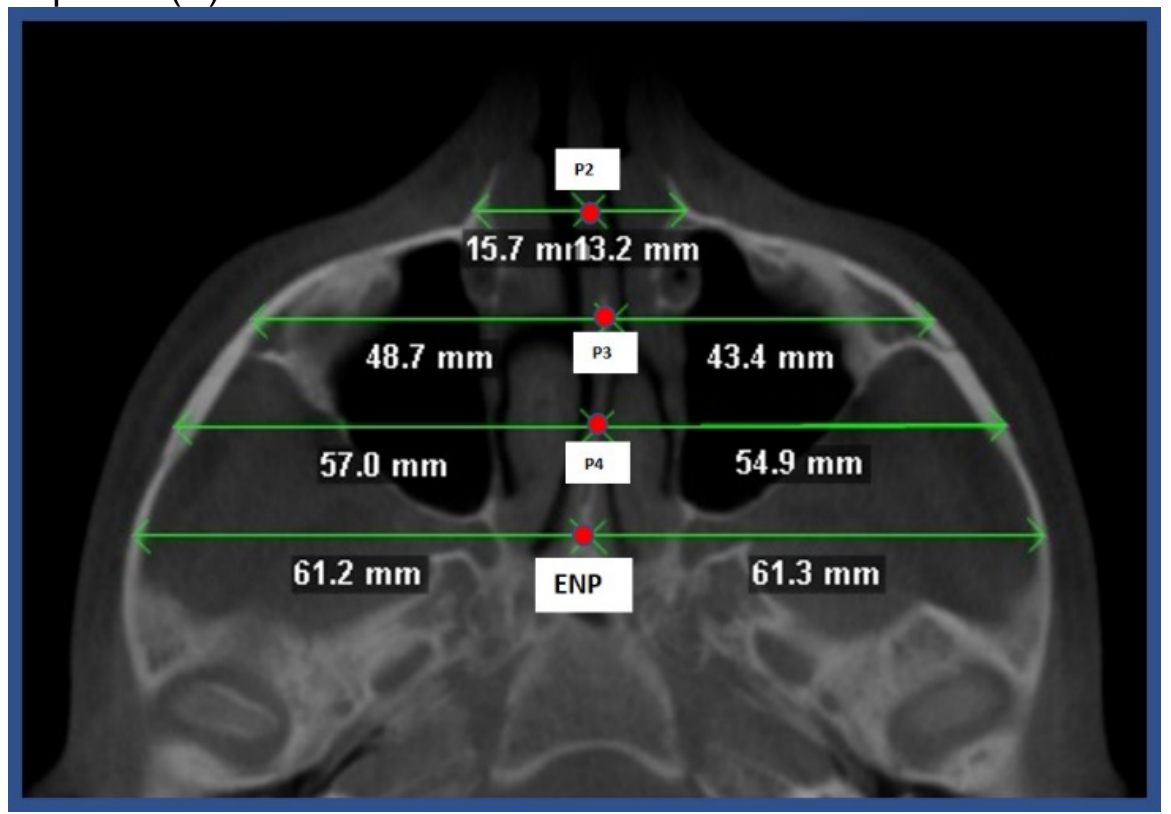




\subsection{Análise Estatística}

Neste estudo foram utilizados os testes Shapiro-Wilk, com finalidade de avaliar a normalidade, e posteriormente o teste de Bartlet de homogeneidade. Em vista disso foi utilizada a análise de variância (ANOVA), com nível de significância de $5 \%$, para analisar as diferentes medidas em diferentes tempos (pré-operatório, pósoperatório imediato e pós-operatório tardio). Visto que não houve diferença estatisticamente significativa, não foi necessário aplicar o pós-teste de Tukey. Para comparar os lados direito e esquerdo, foi aplicado o teste de $t$ de Student para variáveis independentes. Todos os testes de hipótese desenvolvidos consideraram uma significância de $5 \%$, isto é, a hipótese nula foi rejeitada quando o p-valor foi menor que 0.05 . 
4 Resultados 



\section{RESULTADOS}

Todas as medidas foram realizadas por um único avaliador (RRD), como já realizado anteriormente na literatura (Seeberger et al., 2010; Jensen e RodrigoDomingo, 2017), e 20,07\% da amostra (6 pacientes) foi submetida à reavaliação para teste de coeficiente de correlação de concordância (Kappa), sendo obtido o valor de 0,9958, ou seja, uma correlação quase perfeita (Mcbride e Ltd, 2005).

Um total de 40 pacientes foram pesquisados, sendo que 6 foram excluídos por não realizarem a tomografia no tempo correto, e 8 foram excluídos por não apresentarem janelas tomográficas satisfatórias para avaliar o septo nasal e realizar as medidas propostas.

Portanto, 26 prontuários foram selecionados sendo 14 homens e 12 mulheres, com média de idade de 30,58 anos (mínima de 16 e máxima de 55 anos).

Nas medidas lineares aferidas, a média da distância entre a espinha nasal anterior e posterior foi de 52,21mm. As medidas dos 4 pontos, centralizados em septo nasal, até as paredes laterais direita e esquerda foram informadas na tabela 1.

Tabela 1. Média ( $\mathrm{mm}$ ) e ANOVA para as diferentes medidas em diferentes tempos.

\begin{tabular}{lccccccc}
\hline & \multicolumn{3}{c}{ Pré } & \multicolumn{3}{c}{ Pós Imediato } & \multicolumn{2}{c}{ Pós Tardio } & \\
\cline { 2 - 7 } \multicolumn{1}{c}{ Medidas } & Média & $\begin{array}{c}\text { Desvio } \\
\text { padrão }\end{array}$ & Média & $\begin{array}{c}\text { Desvio } \\
\text { padrão }\end{array}$ & Média & $\begin{array}{c}\text { Desvio } \\
\text { padrão }\end{array}$ & Valor de p \\
\hline ENPdireito & 60.31 & 2.81 & 60.35 & 2.87 & 60.42 & 2.80 & 0.989 \\
ENPesquerdo & 60.08 & 2.25 & 59.97 & 2.18 & 60.00 & 2.33 & 0.983 \\
P4 direito & 55.12 & 3.15 & 55.18 & 3.21 & 55.24 & 3.16 & 0.991 \\
P4 esquerdo & 54.51 & 2.44 & 54.43 & 2.26 & 54.38 & 2.45 & 0.980 \\
P3 direito & 46.92 & 3.36 & 46.97 & 3.42 & 46.85 & 3.25 & 0.992 \\
P3 esquerdo & 46.34 & 3.96 & 46.07 & 3.84 & 46.33 & 3.89 & 0.957 \\
P2 direito & 19.69 & 6.37 & 19.58 & 5.95 & 19.61 & 6.08 & 0.997 \\
P2 esquerdo & 19.99 & 6.61 & 19.32 & 6.31 & 19.2 & 6.39 & 0.885 \\
ENA-ENP & 52.21 & 4.68 & & & & & \\
* diferença estatisticamente significativa $(\mathrm{p}<0.05)$ & & & & \\
\end{tabular}

Para avaliação dos diferentes tempos cirúrgicos - pré-operatório, pósoperatório imediatamente após travamento do disjuntor e pós-operatório tardio - uma nova análise foi feita, e diferenças estatísticas também não foram encontradas, como mostra a Figura 16. 
Figura 16. Gráfico de médias $(\mathrm{mm})$ e desvio padrão para os diferentes tempos (pré, pós imediato e pós tardio), aplicando o ANOVA, com nível de significância de $5 \%$. Como não houve diferença significativa, não foi aplicado o pós-teste de Tukey.

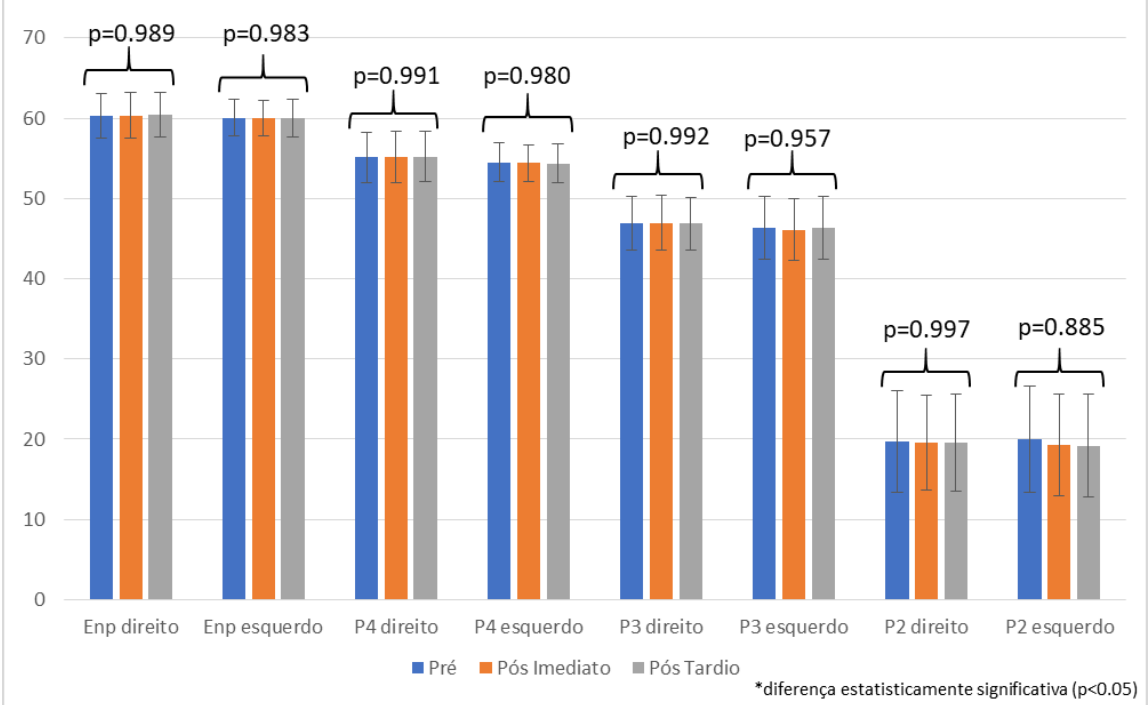

Aplicando-se a análise de variância (ANOVA), não houve diferença estatisticamente significativa entre os diferentes tempos para as diferentes medidas.

Também foram avaliados os lados direito e esquerdo, nos diferentes tempos cirúrgicos. Observou-se que na avaliação dos três tempos independentemente não foram encontradas diferenças significativas, o que demonstra também, indiretamente, uma simetria entre os lados direito e esquerdo da fossa nasal em sua porção inferior, o arco zigomático e o septo nasal em toda a sua extensão, como retratam as figuras 17,18 e 19. 
Figura 17. Gráfico de médias $(\mathrm{mm})$ e desvio padrão para o préoperatório comparando os lados direito e esquerdo, aplicando o teste $\mathrm{t}$ de Student para variáveis independentes. ${ }^{*}$ Diferença estatisticamente significativa $(p<0.05)$.

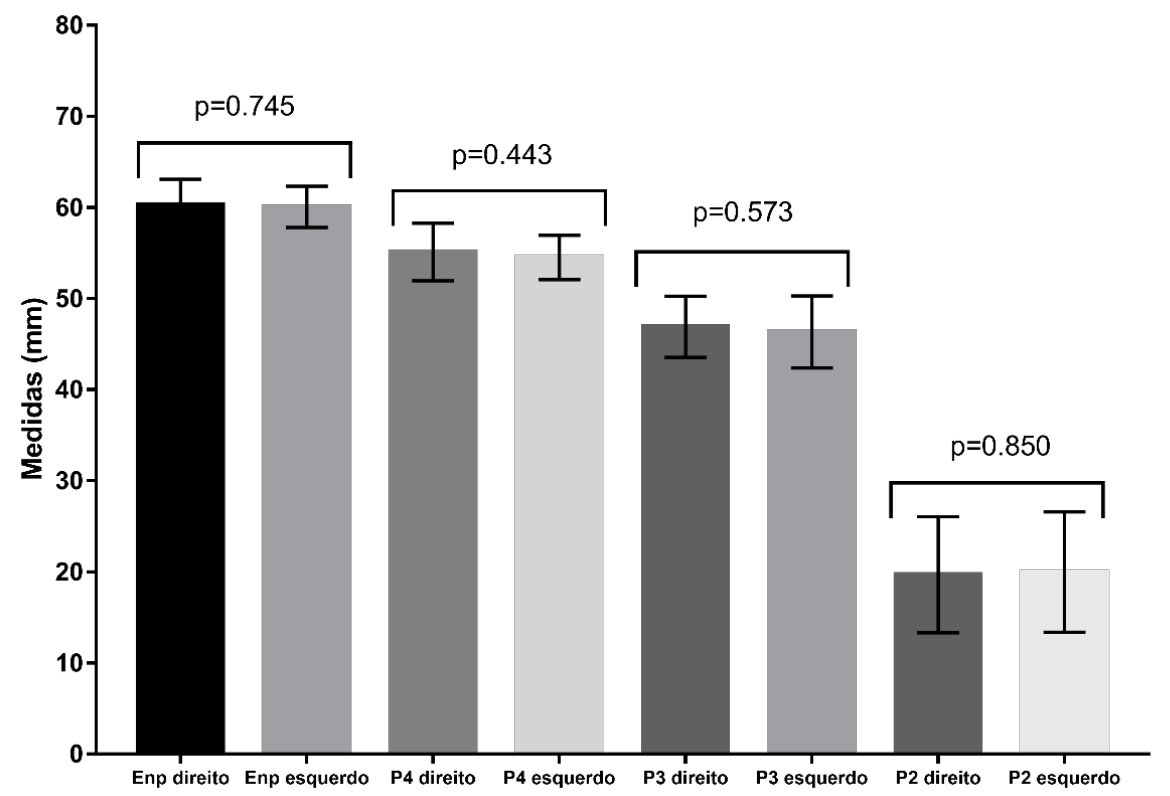

Figura 18. Gráfico de médias $(\mathrm{mm})$ e desvio padrão para o pósoperatório imediato comparando os lados direito e esquerdo, aplicando $o$ teste $t$ de Student para variáveis independentes. *Diferença estatisticamente significativa $(p<0.05)$.

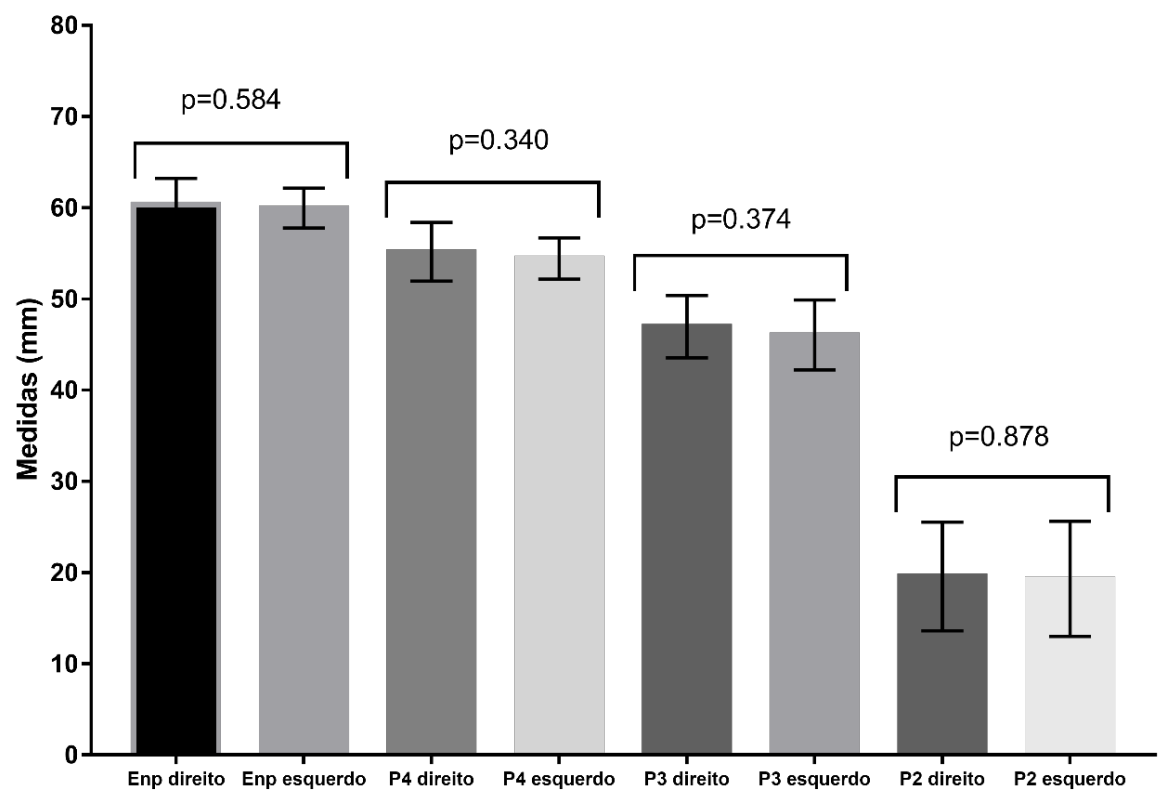


Figura 19. Gráfico de médias $(\mathrm{mm})$ e desvio padrão para o pósoperatório tardio comparando os lados direito e esquerdo, aplicando o teste $\mathrm{t}$ de Student para variáveis independentes. *Diferença estatisticamente significativa $(p<0.05)$.

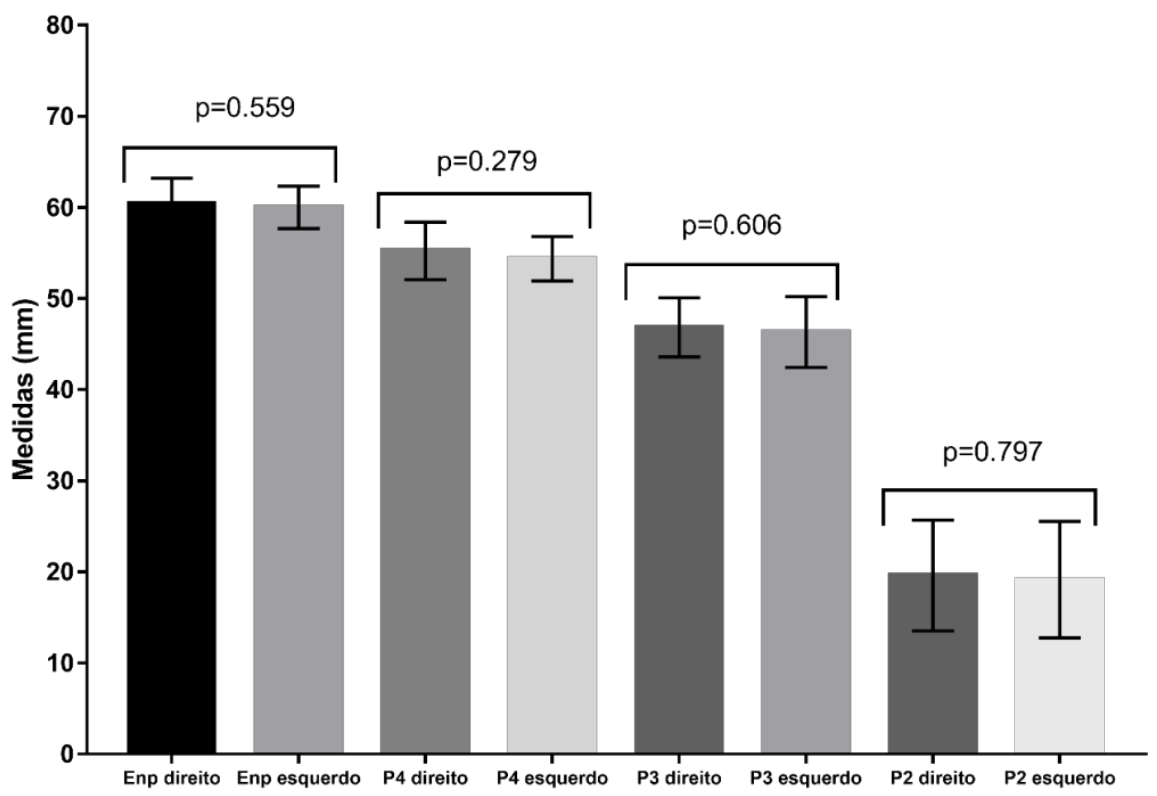

Quando comparados os lados direito e esquerdo para os tempos (pré, pós e tardio), não houve diferença estatisticamente significativa para as diferentes medidas. 



\section{DISCUSSÃO}

Os resultados encontrados no estudo não apontam nenhuma alteração quanto à inserção ou curvatura do septo nasal ósseo em procedimentos de ERMAC ao longo dos diferentes momentos estudados. As análises entre os tempos e dentro dos mesmos tempos cirúrgicos não apresentaram diferenças significativas de deslocamento ou de simetria do septo nasal, tomando por referência a sua base óssea ou o esqueleto fixo circundante. Estes resultados corroboram com o estudo de Schwarz et al. (1985), que não encontraram diferenças significativas de desvio de septo nasal quando avaliaram 9 pacientes submetidos a ERMAC sem osteotomia do septo nasal, porém com realização de osteotomias em parede lateral maxilar, junção pterigomaxilar e linha média palatina. A diferença de técnica cirúrgica do presente estudo para o de Schwarz se encontra na osteotomia da junção pterigomaxilar, considerada um pilar de força posterior.

Um estudo recente comparou clinicamente e através de tomografias dois grupos submetidos a ERMAC, sendo um com realização de osteotomia em base nasal na sua inserção com a maxila e outro sem, ambos com soltura da junção pterigomaxilar, em uma amostra contendo 20 pacientes, sendo 10 de cada grupo, e também não encontrou diferenças angulares significativas inerentes ao septo nasal em períodos pré e pós-operatórios, concluindo que a realização de osteotomias em região de septo era desnecessária (Jensen e Rodrigo-Domingo, 2017). Em um estudo de língua alemã de 2010, Seeberguer e colaboradores avaliaram 19 pacientes submetidos à ERMAC incluindo soltura da junção pterigomaxilar quanto a possíveis desvios em septo nasal, e também não encontraram diferenças significativas em pré e pós-operatório de 6 meses. Os autores também utilizaram tomografias e marcação de pontos de referência em todo o septo nasal em sua porção inferior, porém, ao contrário do presente estudo, as imagens não foram comparadas através de pontos de referência fixos. Além do mais, apesar de não terem encontrado diferenças no posicionamento de septo nasal, encontraram diferenças significativas respiratórias por meio de aumento de via aérea nasal (Seeberger et al., 2010).

Em um estudo de 2012, comparando dois tipos de osteotomias, sendo uma através de três segmentos paramedianos, e o outro pela ERMAC tradicional, ou seja, através de osteotomia central gerando dois segmentos, ambos com liberação 
da junção pterigomaxilar, os autores referem como possível complicação da ERMAC com dois segmentos o desvio do septo e da columela, e que isso foi evitado realizando-se a expansão cirúrgica em 3 segmentos paramedianos (Landes et al., 2012). Em nosso estudo, nenhum desvio estatisticamente significante foi encontrado, além de não constar em prontuário nenhuma alteração notável em columela.

Outros autores recomendaram, em um estudo com 40 pacientes acompanhados por 8 anos, soltar o septo nasal em até $3 \mathrm{~cm}$ posteriormente, juntamente com a espinha nasal anterior, mantendo os dois unidos, o que evitaria desvios do septo e alargamento da região anterior nasal (Woods et al., 1997). Estudos sobre a necessidade da liberação de pilares de força para se conseguir uma expansão satisfatória não são conclusivos, sendo a literatura confusa ao indicar ou não osteotomias ou combinação de osteotomias maxilares, pterigomaxilares, septais e palatinas (Woods et al., 1997; Betts, 2016).

Procedimentos de ERMAC que minimizem osteotomias ao passo que mantenham respostas fisiológicas satisfatórias são desejáveis. Em um estudo de 2008, autores realizaram osteotomias mínimas em pilares zigomáticos e região anterior central de maxila em procedimentos de expansão e obtiveram resultados compatíveis com os relatos da literatura, sem soltar a placa pterigoide. Estes procedimentos menos invasivos trazem vantagens como redução da morbidade e a possibilidade de intervenção sob anestesia local e sedação, em ambiente ambulatorial (De Freitas et al., 2008). O presente estudo vai de encontro com o de De Freitas ao propor que osteotomias em septo nasal não são necessárias, pois as mesmas não trariam benefícios significativos pós-cirúrgicos e aumentariam a morbidade e riscos.

O estudo que propõe a técnica cirúrgica utilizada no presente trabalho avaliou a ERMAC de 19 pacientes no período de 1982 a 1989, e não observou necessidade de se soltar o septo nasal e a junção pterigomaxilar, o que, segundo seus autores, é uma fonte de complicações cirúrgicas. Evitando-se essas possíveis complicações, este procedimento pode ser realizado com segurança em ambiente ambulatorial (Bays, Robert A. e Greco, Joan M., 1992), assim como propõem outros artigos, que também citam as vantagens de se utilizar uma técnica menos traumática, não soltando a junção pterigomaxilar e o septo nasal de sua base maxilar (Marin et al., 2009). 
Uma diferença técnica comum entre o presente estudo e outros citados anteriormente, é que a equipe de residência em Cirurgia e Traumatologia BucoMaxilo-Faciais da Faculdade de Odontologia de Ribeirão Preto da Universidade de São Paulo, responsável por todas as cirurgias deste estudo, não realiza a osteotomia da placa pterigoide durante o procedimento de ERMAC. Outro detalhe importante é que houve simetria aparente no septo nasal, sem desvios significativos em sua extensão anteroposterior, o que se preservou no decorrer da expansão inclusive após o travamento. Seeberger e colaboradores referem que a ausência da separação da placa pterigoide pode fazer com que haja uma acentuada abertura em forma de $\mathrm{V}$ no procedimento de expansão, cuja abertura maior é na região anterior (Seeberger et al., 2010). Já o estudo de Pogrel e colaboradores não sentiram necessidade de soltar o mesmo pilar de força para obterem bons resultados clínicos (Pogrel et al., 1992). O travamento após a cirurgia utilizado na presente pesquisa foi de 6 meses, 3 meses a mais do que a pesquisa realizada no ano de 2010 por Seeberger et al. (2010), a qual também não encontrou diferenças significativas no deslocamento de septo nasal após o procedimento de ERMAC.

Segundo alguns autores, a remoção do septo da sua base no palato evitaria o seu desvio, o seu deslocamento lateral e alteração das vias aéreas nasais durante a fase de distração (Betts et al., 1995; Betts, 2016), o que não foi observado no presente estudo. Em nenhum momento no pré ou pós-operatório o septo nasal se movimentou de forma agressiva ou obstruiu alguma porção nasal. Ao invés disso, o mesmo se manteve em posição simétrica em fossa nasal, e não apresentou desvios notáveis estatisticamente. Isso permite contraindicar a sua remoção da base óssea durante a ERMAC, o que pode aumentar a morbidade trans e pós-operatórias, como sangramento e dor (Politis, 2012).

Alguns pesquisadores sugerem, ainda, que um possível desvio do septo nasal pode estar relacionado à pressão do tubo nasotraqueal durante a anestesia geral e osteotomia Le Fort I (Ibrahim et al., 2014), e não ao procedimento cirúrgico propriamente dito.

Outros resultados na literatura sugerem também que a ERMAC com aparelhos dento-suportados mais tradicionalmente utilizados, como, por exemplo, o Hyrax, aumentam significantemente a largura da maxila, geram o deslocamento axial dos elementos dentários vestibularmente, aumentam o tamanho do assoalho 
nasal, principalmente em região anterior, porém não afetam em níveis significativos o septo nasal (Seeberger et al., 2011).

O autor Pedro Vinha, em sua tese de doutorado em 2011, relacionada à expansão de maxila para resolução de problemas relacionados à apneia obstrutiva do sono, refere ser comum a ocorrência de obstrução nasal nos primeiros dias após a cirurgia de ERMAC, apesar de ser raro que esse problema se perpetue devido ao desvio do septo nasal, mas que, caso ocorra, torna-se necessária a correção cirúrgica (Vinha, 2015).

Contrariamente ao presente trabalho, Mortellaro e colaboradores atribuem grande parte da incidência de recidiva da ERMAC ao septo nasal. Tais autores estudaram 61 pacientes submetidos a uma técnica de ERMAC com soltura do septo nasal, principalmente em região de vômer, além de osteotomia em linha média, e referiram boa estabilidade a curto e longo prazo, recomendando sua soltura em toda a sua extensão (Mortellaro et al., 2010).

Em um artigo de 2011, onde 15 pacientes submetidos à ERMAC foram avaliados em radiografias cefalométricas em três ocasiões: pré-operatória, no momento do travamento do expansor e seis meses após o travamento, foi observado um aumento da porção inferior da abertura piriforme, bem como um aumento da distância entre a lateral nasal e o septo nasal. Entretanto, apesar do aumento destas distâncias, nenhuma alteração no posicionamento do septo nasal foi observada (Landim et al., 2011). Este estudo também corrobora com os resultados do presente trabalho, onde nenhum deslocamento estatisticamente significante foi notado.

Semelhantemente aos resultados do nosso estudo, um trabalho avaliou retrospectivamente o desvio do septo nasal em 25 pacientes submetidos a ERMAC, cuja técnica abrangeu osteotomia lateral através do pilar zigomático e osteotomia sagital entre as raízes dos incisivos centrais, através da comparação de TCFCs antes e após 6-8 semanas da cirurgia, e não encontrou desvio ou movimento do septo, descartando a necessidade de osteotomia do mesmo (Reinbacher et al., 2013). 
6 Conclusão 



\section{CONCLUSÃO}

- Não houveram diferenças estatisticamente significativas no posicionamento do septo nasal entre os tempos cirúrgicos analisados. 

RefERÊNCIAS 



\section{REFERÊNCIAS}

ALTUG-ATAC, A. T. et al. Changes in nasal structures following orthopaedic and surgically assisted rapid maxillary expansion. Int J Oral Maxillofac Surg, v. 39, n. 2, p. 129-35, Feb 2010. ISSN 0901-5027.

ANGELL, E. Treatment of irregularity of the permanent or adult teeth. Dental Cosmos, v. 1, n. 1, p. 540-4, 1860.

BARATIERI CDA, L. et al. Transverse effects on the nasomaxillary complex one year after rapid maxillary expansion as the only intervention: a controlled study. Dental Press J Orthod, v. 19, n. 5, p. 79-87, Sep-Oct 2014. ISSN 2176-9451.

BAYS, R. A.; GRECO, J. M. Surgically assisted rapid palatal expansion: an outpatient technique with long-term stability. J Oral Maxillofac Surg, v. 50, n. 2, p. 110-3; discussion 114-5, Feb 1992. ISSN 0278-2391 (Print) 0278-2391.

BAYS, R. A.; GRECO, J. M. Surgically assisted rapid palatal expansion: An outpatient technique with long-term stability. Journal of Oral and Maxillofacial Surgery, v. 50, n. 2, p. 110-113, 1992/02/01/ 1992. ISSN 0278-2391. Disponível em: < http://www.sciencedirect.com/science/article/pii/027823919290352Z >.

BELL, W. H.; EPKER, B. N. Surgical-orthodontic expansion of the maxilla. American journal of orthodontics, v. 70, n. 5, p. 517-528, 1976. ISSN 0002-9416.

BETTS, N. J. Surgically Assisted Maxillary Expansion. Atlas of the Oral and Maxillofacial Surgery Clinics, v. 24, n. 1, p. 67-77, 2016/03/01/ 2016. ISSN 10613315. em: http://www.sciencedirect.com/science/article/pii/S1061331515000591 >.

BETTS, N. J. et al. Diagnosis and treatment of transverse maxillary deficiency. Int $\mathbf{J}$ Adult Orthodon Orthognath Surg, v. 10, n. 2, p. 75-96, 1995. ISSN 0742-1931 (Print) 0742-1931.

BLACK, N. M. J. J. O. T. A. M. A. THE RELATION BETWEEN DEVIATION OF THE NASAL SEPTUM AND IRREGULARITIES OF THE TEETH AND JAW: FROM A RHINOLOGIST'S STANDPOINT. v. 52, n. 12, p. 943-945, 1909. ISSN 0002-9955.

BROWN, G. J. D. C. The application of orthodontia principles to the prevention of nasal disease. v. 45, p. 765-775, 1903.

BROWN, G. V. I. The surgery of oral and facial diseases and malformations: their diagnosis and treatment including plastic surgical reconstruction. Lea \& Febiger, 1938.

BYLOFF, F. K.; MOSSAZ, C. F. Skeletal and dental changes following surgically assisted rapid palatal expansion. Eur J Orthod, v. 26, n. 4, p. 403-9, Aug 2004. ISSN 0141-5387 (Print) 0141-5387. 
CHAMBERLAND, S.; PROFFIT, W. R. Closer look at the stability of surgically assisted rapid palatal expansion. J Oral Maxillofac Surg, v. 66, n. 9, p. 1895-900, Sep 2008. ISSN 0278-2391.

CODIVILLA, A. On the means of lengthening, in the lower limbs, the muscles and tissues which are shortened through deformity. 1904. Clin Orthop Relat Res, n. 301, p. 4-9, Apr 1994. ISSN 0009-921X (Print) 0009-921x.

DE FREITAS, R. R. et al. Surgically assisted maxillary expansion in adults: prospective study. International Journal of Oral and Maxillofacial Surgery, v. 37, n. 9, p. 797-804, 2008/09/01/ 2008. ISSN 0901-5027. Disponível em: < http://www.sciencedirect.com/science/article/pii/S090150270800163X >.

DEEB, W. et al. Changes in nasal volume after surgically assisted bone-borne rapid maxillary expansion. Am J Orthod Dentofacial Orthop, v. 137, n. 6, p. 782-9, Jun 2010. ISSN 0889-5406.

GRABER, T. M.; VANARSDALL, R. L. Orthodontics: current principles and techniques. CV Mosby, 1994. ISBN 0801665906.

GURGEL, J. A.; TIAGO, C. M.; NORMANDO, D. Transverse changes after surgically assisted rapid palatal expansion. Int J Oral Maxillofac Surg, v. 43, n. 3, p. 316-22, Mar 2014. ISSN 0901-5027.

HAAS, A. J. Rapid expansion of the maxillary dental arch and nasal cavity by opening the midpalatal suture. The Angle Orthodontist, v. 31, n. 2, p. 73-90, 1961. ISSN 0003-3219.

HAN, U. A.; KIM, Y.; PARK, J. U. Three-dimensional finite element analysis of stress distribution and displacement of the maxilla following surgically assisted rapid maxillary expansion. J Craniomaxillofac Surg, v. 37, n. 3, p. 145-54, Apr 2009. ISSN 1010-5182.

HUR, M. S. et al. Morphological Patterns and Variations of the Nasal Septum Components and Their Clinical Implications. J Craniofac Surg, v. 27, n. 8, p. 21642167, Nov 2016. ISSN 1049-2275.

IBRAHIM, A. et al. Combating nasal septum deviation in le fort 1 orthognathic surgery complications, with submental intubation. J Clin Diagn Res, v. 8, n. 6, p. Zc46-8, Jun 2014. ISSN 2249-782X (Print)0973-709x.

JENSEN, T.; RODRIGO-DOMINGO, M. Surgically assisted rapid maxillary expansion (SARME) with or without intraoperative releasing of the nasal septum. Oral Surgery, Oral Medicine, Oral Pathology and Oral Radiology, v. 123, n. 3, p. e85-e90, 2017/03/01/ 2017. ISSN 2212-4403. Disponível em: < http://www.sciencedirect.com/science/article/pii/S2212440316306162 >.

KLAPPER, L.; GEORGE, R. A new telescopic maxillary expander. J Clin Orthod, v. 29, n. 2, p. 114-6, Feb 1995. ISSN 0022-3875 (Print) 0022-3875. 
LANDES, C. A. et al. Advantages and limits of 3-segment (paramedian) versus 2segment (median) surgically assisted rapid maxillary expansion (SARME). Oral Surg Oral Med Oral Pathol Oral Radiol, v. 113, n. 1, p. 29-40, Jan 2012.

LANDIM, F. S. et al. Repercussions of surgically assisted maxillary expansion on nose width and position of septum and inferior nasal conchae. Int J Med Sci, v. 8, n. 8, p. 659-66, 2011. ISSN 1449-1907.

LIN, L. et al. Tooth-borne vs bone-borne rapid maxillary expanders in late adolescence. Angle Orthod, v. 85, n. 2, p. 253-62, Mar 2015. ISSN 0003-3219.

MARIN, C.; GIL, J. N.; LIMA, S. M., JR. Surgically assisted palatine expansion in adult patients: evaluation of a conservative technique. J Oral Maxillofac Surg, v. 67, n. 6, p. 1274-9, Jun 2009. ISSN 0278-2391.

MCBRIDE, G. J. C. C. C. H. N. I. O. W.; LTD, A.-S. R. A proposal fo strength-ofagreement criteria for Lin. S. 2005.

MENON, S.; MANERIKAR, R.; SINHA, R. Surgical management of transverse maxillary deficiency in adults. J Maxillofac Oral Surg, v. 9, n. 3, p. 241-6, Sep 2010. ISSN 0972-8270.

MOMMAERTS, M. Y. Transpalatal distraction as a method of maxillary expansion. British Journal of Oral and Maxillofacial Surgery, v. 37, n. 4, p. 268-272, 1999/08/01/ 1999. ISSN 0266-4356. Disponível em: < http://www.sciencedirect.com/science/article/pii/S0266435699901274 >.

MORTELLARO, C. et al. Rapid expansion of the palate with a new surgical technique. J Craniofac Surg, v. 21, n. 3, p. 892-9, May 2010. ISSN 1049-2275.

OLIVEIRA DE FELIPPE, N. L. et al. Relationship between rapid maxillary expansion and nasal cavity size and airway resistance: short- and long-term effects. Am J Orthod Dentofacial Orthop, v. 134, n. 3, p. 370-82, Sep 2008. ISSN 0889-5406.

PEREIRA-FILHO, V. A. et al. Volumetric upper airway assessment in patients with transverse maxillary deficiency after surgically assisted rapid maxillary expansion. International Journal of Oral and Maxillofacial Surgery, v. 43, n. 5, p. 581-586, 2014/05/01/ 2014. ISSN 0901-5027. Disponível em: < http://www.sciencedirect.com/science/article/pii/S0901502713011661 >.

POGREL, M. A. et al. Surgically assisted rapid maxillary expansion in adults. Int $\mathbf{J}$ Adult Orthodon Orthognath Surg, v. 7, n. 1, p. 37-41, 1992. ISSN 0742-1931 (Print) 0742-1931.

POLITIS, C. Life-threatening haemorrhage after 750 Le Fort I osteotomies and 376 SARPE procedures. International Journal of Oral and Maxillofacial Surgery, v. 41, n. 6, p. 702-708, 2012/06/01/ 2012. ISSN 0901-5027. Disponível em: < http://www.sciencedirect.com/science/article/pii/S0901502712000835 >.

PROFFIT, W. R.; TURVEY, T. A.; PHILLIPS, C. Orthognathic surgery: a hierarchy of stability. Int J Adult Orthodon Orthognath Surg, v. 11, n. 3, p. 191-204, 1996. ISSN 0742-1931 (Print) 0742-1931. 
. The hierarchy of stability and predictability in orthognathic surgery with rigid fixation: an update and extension. Head Face Med, v. 3, p. 21, Apr 30 2007. ISSN 1746-160x.

REINBACHER, K. E. et al. Surgically assisted rapid maxillary expansion: feasibility of not releasing the nasal septum. International Journal of Oral and Maxillofacial Surgery, v. 42, n. 3, p. 321-325, 2013/03/01/ 2013. ISSN 0901-5027. Disponível em: < http://www.sciencedirect.com/science/article/pii/S0901502712004122 >.

SCHWARZ, G. M. et al. Tomographic assessment of nasal septal changes following surgical-orthodontic rapid maxillary expansion. American Journal of Orthodontics, v. 87 , n. 1, p. 39-45, 1985/01/01/ 1985. ISSN 0002-9416. Disponível em: < http://www.sciencedirect.com/science/article/pii/0002941685901721 >.

SEEBERGER, R. et al. Changes after surgically-assisted maxillary expansion (SARME) to the dentoalveolar, palatal and nasal structures by using tooth-borne distraction devices. Br J Oral Maxillofac Surg, v. 49, n. 5, p. 381-5, Jul 2011. ISSN 0266-4356.

SEEBERGER, R. et al. [Surgically assisted rapid maxillary expansion. Effects on the nasal airways and nasal septum]. Hno, v. 58, n. 8, p. 806-11, Aug 2010. ISSN 00176192.

VINHA, P. P. Efeitos da expansão rápida da maxila cirurgicamente assistida na síndrome da apneia obstrutiva do sono, na sonolência diurna e na morfologia da via aérea. 2015. Universidade de São Paulo

WOODS, M.; WIESENFELD, D.; PROBERT, T. Surgically-assisted maxillary expansion. Aust Dent J, v. 42, n. 1, p. 38-42, Feb 1997. ISSN 0045-0421 (Print) 0045-0421. 
ApÊNDICES 

APÊNDICE A - Protocolo de atendimento da equipe de residência em Cirurgia e Traumatologia Buco-Maxilo-Faciais

\section{Protocolo de Atendimento}

Ribeirão Preto, 1

Referente paciente:

Protocolo de Atendimento para Pacientes a serem submetidos a Cirurgia para Disjunção Palatina

1. Realizar (obter) moldagem diagnóstico em gesso das arcadas dentárias superiores e inferiores;

2. Solicitar tomografia pré-operatória (enviar carta protocolo à equipe radiologia)

3. Instalar o aparelho disjuntor Hirax (enviar carta protocolo ao ortodontista);

4. Realização da cirurgica conforme professores orientadores do caso;

5. Após um período de latência de 1 semana, serão indicadas 2 ativações (2/4 de volta) pela manhã e mais 2 ativações (2/4 de volta) a tarde;

6. Após se obter a quantidade de sobrecorreção considerada por nós adequada, o paciente deverá:

a) Ser encaminhado para realização da tomografia (enviar carta protocolo à equipe radiologia)

b) Ser encaminhado novamente ao ortodontista para travamento do aparelho conforme protocolo submetido ao ortodontista (caso o ortodontista não realizar o travamento com resina e fio de aço, o mesmo deverá ser confeccionado pelo cirurgião responsável pelo caso)

7. A retirada do aparelho disjuntor será realizada após a solicitação por escrito feita pelo cirurgião responsável pelo caso, com aval do professor orientador;

8. Solicitar tomografia pós-operatória final 
APÊNDICE B - Protocolo ortodôntico do tratamento

Referente paciente:

Prezado Dr.

Conforme o protocolo de atendimento do Curso de Residência em Cirurgia e Traumatologia Buco-Maxilo-Faciais dos pacientes a serem submetidos a cirurgia para disjunção palatina, solicitamos os seguintes itens obrigatórios pré, trans e pós cirúrgicos:

1. Instalar o aparelho disjuntor Hirax, se possível com as bandas posicionadas em $1^{\circ} \mathrm{s}$ pré-molares e $1^{\circ} \mathrm{s}$ molares. $\mathrm{O}$ aparelho deve ter extensão palatina de mesial de canino a distal de segundo molar, em ambos os lados confeccionado com fio $0,8 \mathrm{~mm}$. Nenhum dispositivo deve ser colocado por vestibular.

2. Deixar o aparelho Hirax a uma distância mínima de $2 \mathrm{~mm}$ da mucosa palatina, de modo a evitar o contato do aparelho com a mucosa durante a ativação.

3. Após um período de latência de 1 semana, serão indicadas 2 ativações (2/4 de volta) pela manhã e mais 2 ativações ( $2 / 4$ de volta) a tarde.

4. Após se obter a quantidade de sobrecorreção considerada por nós adequada, o paciente será encaminhado a V.Sa. para averiguação da mesma. Se houver concordância, o aparelho deverá ser travado.

5. O travamento do disjuntor deverá ser realizado com fio de aço e resina acrílica.

6. A retirada do aparelho disjuntor será realizada após a solicitação por escrito feita pelo cirurgião responsável pelo caso. $\mathrm{O}$ acompanhamento será realizado com o auxilio de tomografias volumétricas computadorizadas.

7. Em caso de discordância em algum item, entre em contato com o Cirurgião responsável antes do procedimento cirúrgico e instalação do aparelho. 
Anexo 



\section{ANEXO - Parecer do Comitê de Ética em Pesquisa}

Título da Pesquisa: Análise volumétrica dos seios maxilares e linear da cavidade nasal em pacientes submetidos a expansão rápida de maxila cirúrgicamente assistida Pesquisador Responsável: Rafael Rodrigues Dias Área Temática:

Versão: 1

CAAE: 56389416.0 .0000 .5419

Submetido em: 23/05/2016

Instituição Proponente: Universidade de Sao Paulo

Situação da Versão do Projeto: Aprovado

Localização atual da Versão do Projeto: Pesquisador Responsável

Patrocinador Principal: Financiamento Próprio 